\title{
Comparative Cooling Season Performance of Air Distribution Systems in Multistory Townhomes
}

\author{
A. Poerschke, R. Beach, and T. Beggs \\ IBACOS, Inc.
}

August 2016 


\section{NOTICE}

This report was prepared as an account of work sponsored by an agency of the United States government. Neither the United States government nor any agency thereof, nor any of their employees, subcontractors, or affiliated partners makes any warranty, express or implied, or assumes any legal liability or responsibility for the accuracy, completeness, or usefulness of any information, apparatus, product, or process disclosed, or represents that its use would not infringe privately owned rights. Reference herein to any specific commercial product, process, or service by trade name, trademark, manufacturer, or otherwise does not necessarily constitute or imply its endorsement, recommendation, or favoring by the United States government or any agency thereof. The views and opinions of authors expressed herein do not necessarily state or reflect those of the United States government or any agency thereof.

Available electronically at SciTech Connect http:/www.osti.gov/scitech

Available for a processing fee to U.S. Department of Energy and its contractors, in paper, from:

U.S. Department of Energy

Office of Scientific and Technical Information

P.O. Box 62

Oak Ridge, TN 37831-0062

OSTI http://www.osti.gov

Phone: 865.576.8401

Fax: 865.576.5728

Email: reports@osti.gov

Available for sale to the public, in paper, from:

U.S. Department of Commerce

National Technical Information Service

5301 Shawnee Road

Alexandria, VA 22312

NTIS http://www.ntis.gov

Phone: 800.553 .6847 or 703.605 .6000

Fax: 703.605.6900

Email: orders@ntis.gov 


\section{Comparative Cooling Season Performance of Air Distribution Systems in Multistory Townhomes}

Prepared for:

The National Renewable Energy Laboratory

On behalf of the U.S. Department of Energy's Building America Program

Office of Energy Efficiency and Renewable Energy

15013 Denver West Parkway

Golden, CO 80401

NREL Contract No. DE-AC36-08GO28308

Prepared by:

A. Poerschke, R. Beach, and T. Beggs

IBACOS, Inc.

2214 Liberty Avenue

Pittsburgh, PA 15222

NREL Technical Monitor: Stacey Rothgeb

Prepared under Subcontract No. KNDJ-0-40341-05

August 2016 
The work presented in this report does not represent performance of any product relative to regulated minimum efficiency requirements.

The laboratory and/or field sites used for this work are not certified rating test facilities. The conditions and methods under which products were characterized for this work differ from standard rating conditions, as described.

Because the methods and conditions differ, the reported results are not comparable to rated product performance and should only be used to estimate performance under the measured conditions. 


\section{Contents}

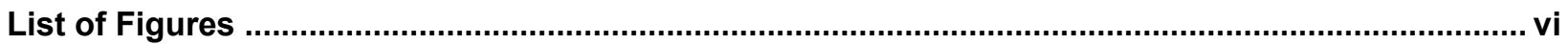

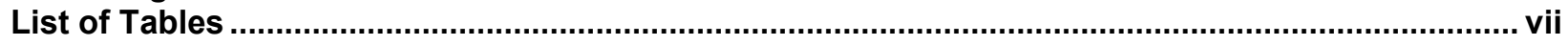

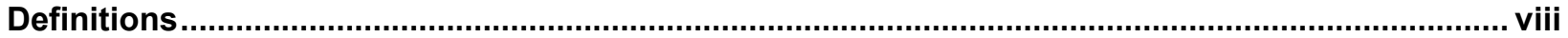

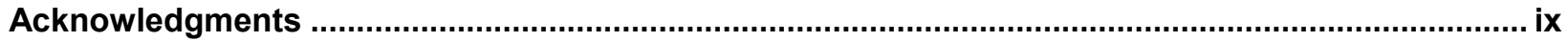

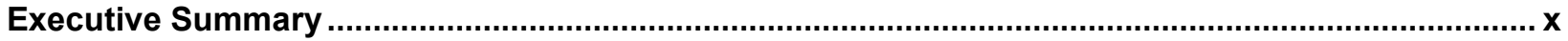

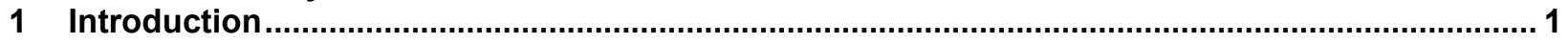

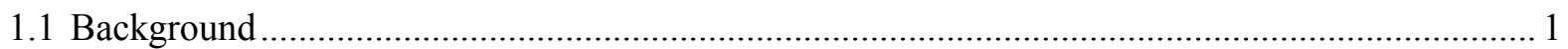

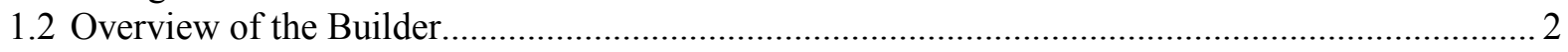

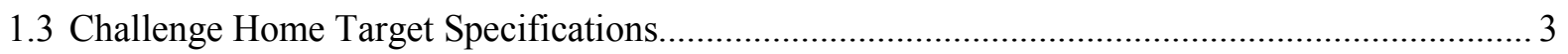

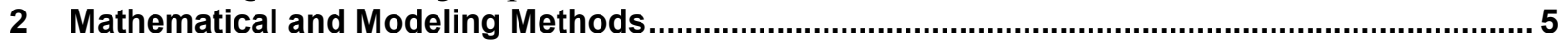

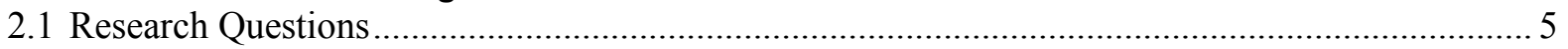

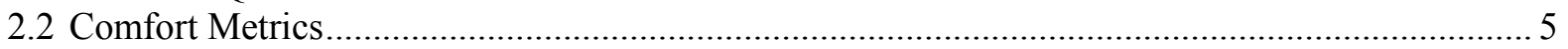

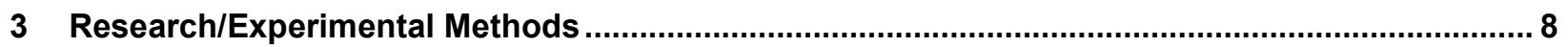

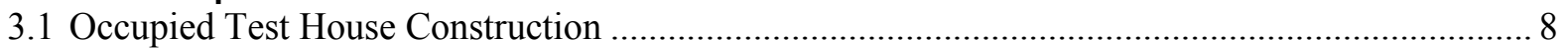

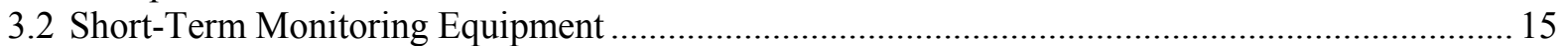

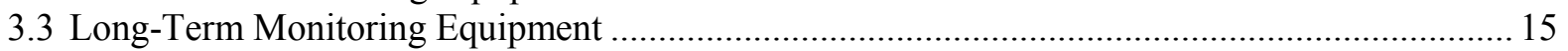

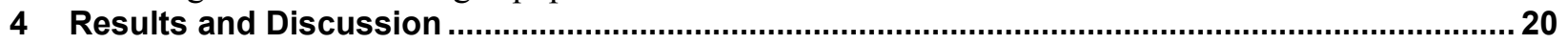

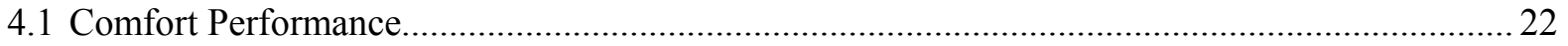

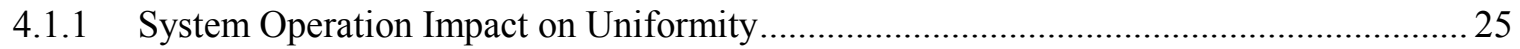

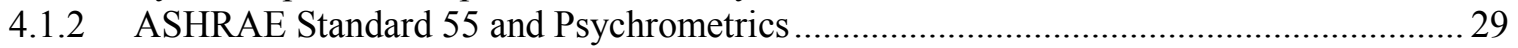

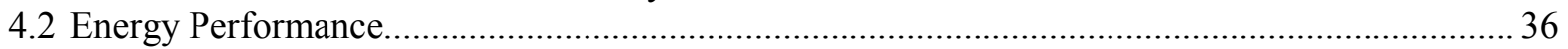

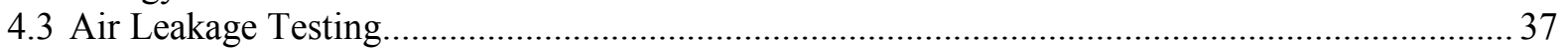

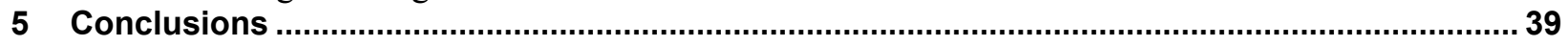

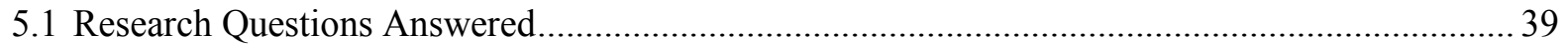

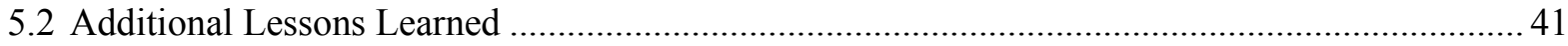

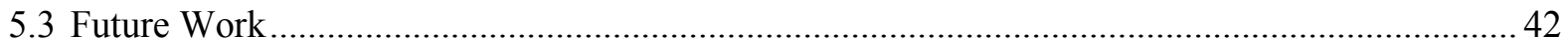

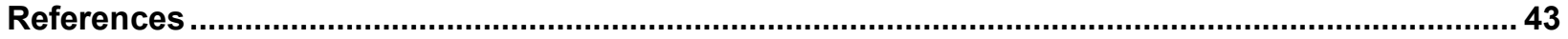




\section{List of Figures}

Figure 1. Diagram showing ACCA Manual RS and drift/ramp failures

Figure 2. Probability of drawing an incorrect conclusion in the ACCA analysis for sensors with an error of $0.38^{\circ} \mathrm{F}$

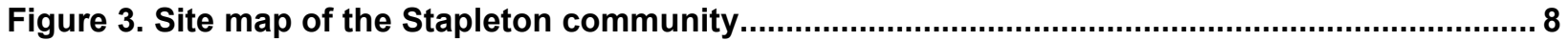

Figure 4. Orthographic drawing of the test homes (not to scale) ..................................................... 9

Figure 5. Plan view drawing of the test home arrangement ........................................................... 9

Figure 6. Front elevation showing all six townhomes (doors facing north) ..................................... 10

Figure 7. Back elevation showing all six townhomes (garages facing south) ................................. 10

Figure 8. Small-diameter trunk-and-branch plenum on the third floor of Home A1 ........................ 13

Figure 9. Small-diameter upflow air handling unit on the second floor of Home A2 ...................... 14

Figure 10. Register for the builder's standard system, showing a balancing damper and mastic.. 15

Figure 11. Room sensor and thermostat ............................................................................... 17

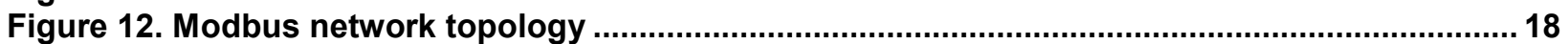

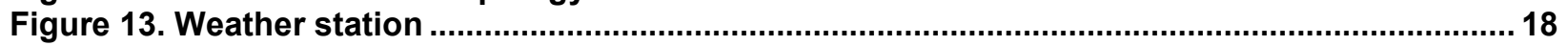

Figure 14. Outdoor temperature measurements at the test site .................................................... 20

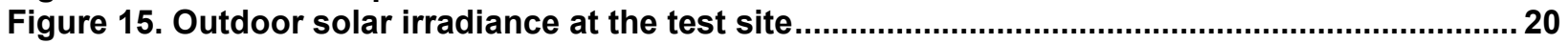

Figure 16. Carbon dioxide levels in the test houses .................................................................... 21

Figure 17. Hourly average thermostat temperature for each house ............................................. 22

Figure 18. Room-to-room temperature difference by house .......................................................... 22

Figure 19. Room-to-thermostat temperature relationship ......................................................... 24

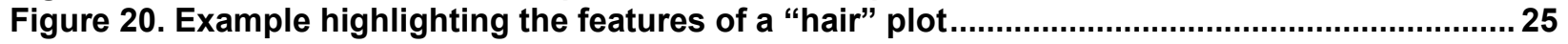

Figure 21. Home A1: Room-to-room temperature change during operation ......................................26

Figure 22. Home A2: Room-to-room temperature change during operation ...................................26

Figure 23. Home B1: Room-to-room temperature change during operation .................................... 27

Figure 24. Home B2: Room-to-room temperature change during operation .................................... 27

Figure 25. Home B3: Room-to-room temperature change during operation .................................... 28

Figure 26. Hourly average room-to-room temperature versus outdoor temperature ........................29

Figure 27. Home A1: Small diameter-room temperature versus system runtime........................... 30

Figure 28. Home A2: Small diameter-room temperature versus system runtime............................ 30

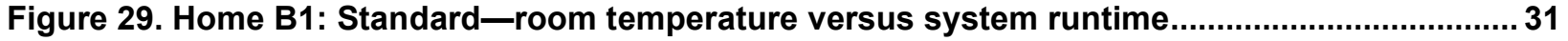

Figure 30. Home B2: Standard-room temperature versus system runtime ................................... 31

Figure 31. Home B3: Standard-room temperature versus system runtime ..................................... 32

Figure 32. Home A1: Small-diameter-psychrometric chart ............................................................. 33

Figure 33. Home A2: Small diameter-psychrometric chart ............................................................. 33

Figure 34. Home A3: Mini-split heat pump_psychrometric chart...................................................... 34

Figure 35. Home B1: Standard-psychrometric chart .................................................................. 34

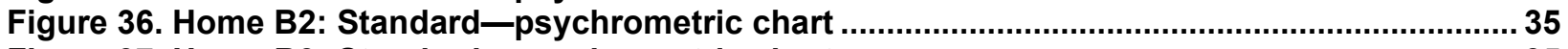

Figure 37. Home B3: Standard-psychrometric chart .................................................................... 35

Figure 38. Cumulative energy consumed by the cooling equipment in each townhome .................36

Figure 39. Cumulative whole-house electrical energy consumed by each townhome ..................... 37

Unless otherwise noted, all figures were created by IBACOS. 


\section{List of Tables}

Table 1. Results of Preliminary Challenge Home Specification Analysis for Floor Plan $1120 \ldots \ldots \ldots . . .4$

Table 2. ASHRAE Standard 55 Temperature Changes over Time .................................................... 5

Table 3. Home Enclosure Specifications ...................................................................................... 11

Table 4. Calculated Load and Installed Equipment and Rated Leakage ....................................... 12

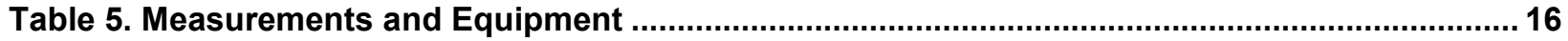

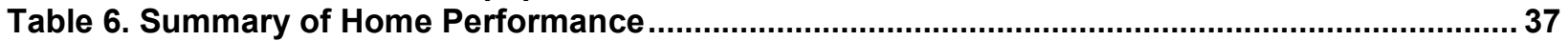

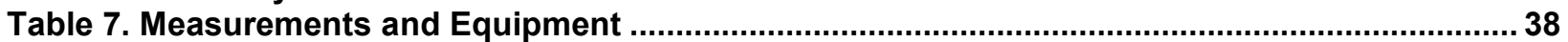

Unless otherwise noted, all tables were created by IBACOS. 


\section{Definitions}

ACCA

ACH50

BEopt ${ }^{\mathrm{TM}}$

Btu

CFM

DOE

ELA

HERS

HSPF

HVAC

SEER

SHGC

ZERH
Air Conditioning Contractors of America

Air Changes per Hour at 50 Pascals

Building Energy Optimization Software

British Thermal Unit

Cubic Feet per Minute

U.S. Department of Energy

Effective Leakage Area

Home Energy Rating System

Heating Seasonal Performance Factor

Heating, Ventilating, and Air Conditioning

Seasonal Energy Efficiency Ratio

Solar Heat Gain Coefficient

Zero Energy Ready Home 


\section{Acknowledgments}

The authors acknowledge Gene Myers and Bill Rectanus of New Town Builders for their interest in the U.S. Department of Energy Challenge Home Program, their support of these research efforts, and their commitment to high performance and value in the residential marketplace. The authors also would like to thank Unico, Inc. for contributing technical knowledge to this project. 


\section{Executive Summary}

New Town Builders ${ }^{1}$ constructed six townhome units in two triplexes in Denver, Colorado. The U.S. Department of Energy's Building America research team IBACOS worked with this builder to test the performance of two new heating, ventilating, and air-conditioning (HVAC) systems against the builder's standard system. Two units were conditioned using the Unico air-source heat pump system, which uses a small-diameter and high-velocity air delivery system, and one unit was conditioned using the Unico ductless mini-split heat pump system. Three townhomes were conditioned with the builder's standard system, which consists of a Carrier gas furnace with $92 \%$ annual fuel utilization efficiency and a Carrier air conditioner with a seasonal energy efficiency ratio of 13 .

Construction of the two triplex townhouse buildings with identical solar orientations and enclosure specifications was completed in March 2015, and the monitoring system installation continued into the second quarter of 2015. The six townhome units in the two buildings were sold, and five units were occupied as of this writing. The last to sell was the unit with the minisplit heat pump head units inside the home. It sold in mid-July 2015 as an investment property; the owner intended to rent it out. The unit previously had been under contract for sale, but the aesthetics of the mini-split head units ultimately deterred that interested buyer.

Because all units have an identical orientation and similar floor plans, this research represented a unique opportunity for a side-by-side comparison of system performance. The researchers' intent was to identify real-world performance differences between the entire small-diameter system and the builder's standard system, which includes the compressor, air handling unit, and air distribution systems. Occupant behavior was the major external factor that influenced a direct comparison of each system. Heating season data could not be captured during the project period because of delays in constructing the homes. Analysis of the cooling season performance revealed several findings:

- The small-diameter air distribution system is providing substantially better air mixing, better floor-to-floor temperature uniformity, and ultimately better comfort than the standard air distribution systems. The partner builder has been concerned about stratification within its three-story townhomes - even as the thermal performance of the building shell has improved with the builder's commitment to high-performance homes. During a test period of 9 days in August 2015, the average room-to-room temperature difference in the small-diameter homes was $2.4^{\circ} \mathrm{F}$ and $2.1^{\circ} \mathrm{F}$; in the builder's standard home, it was $2.6^{\circ} \mathrm{F}, 4.8^{\circ} \mathrm{F}$, and $6.6^{\circ} \mathrm{F}$.

- A study of system cycling and temperature drift revealed that the standard and smalldiameter systems are meeting industry criteria for rate of change of space temperature when the systems cycle on and off. The small-diameter system is providing more uniform temperatures during operation cycles. Furthermore, the small-diameter system operation has a more gradual impact on room temperature drift and recovery despite the system's observed tendency to short-cycle.

\footnotetext{
${ }^{1}$ New Town Builders is now known as Thrive Home Builders.
} 
There may be several reasons for the improved comfort. Ductwork for both systems was located in conditioned space. The air handling unit for the builder's standard system was located in a large closet on the first floor. With this configuration, the top floor received less airflow, and air had more time to lose energy through the ductwork boundary. The air handling unit of the small-diameter system was placed on the middle floor of the three-story townhome. Thus, the duct runs were shorter, and a better airflow balance was achieved between the first and third floors. The smaller central air handling unit and small-diameter ductwork allowed the HVAC designer to lay out the ductwork in this ideal configuration. The entire small-diameter air handling unit fit into the second-floor cavity for the supply plenum of the builder's standard system. As a bonus, more closet space was available to the occupants of the townhome with the small-diameter system.

- A clear benefit has not been demonstrated by any of the systems in terms of energy consumption for space conditioning in the cooling season. Electric energy consumed by the cooling equipment during the August 2015 period was $12.1 \mathrm{kWh} /$ day and

$11.4 \mathrm{kWh}$ /day for the small-diameter system and $12.9 \mathrm{kWh}$ /day and $10 \mathrm{kWh} /$ day for the builder's standard system matching homes.

In one townhome, the small-diameter system required some post-occupancy modifications to improve its performance. The air delivery system required physical changes for access behind drywall, such as adjusting the duct bend radius in several locations because of conflicts with framing that was installed after the duct runs were placed. The air outlets had to be relocated to correct the restrictions that were affecting airflow and increasing room noise levels. In another instance, an air outlet was moved to relieve air dumping onto a desk at a stairway landing.

The partner builder initially planned to upgrade the design of the townhomes being built in this development to meet the criteria set forth in the U.S. Department of Energy's Challenge Home National Program Requirements (DOE 2013). During this project, the builder decided that changing the townhome product in this development midstream would be excessively disruptive to its process and business. However, the builder has adopted Challenge Home construction and DOE Zero Energy Ready Home program standards (DOE 2015) into its townhome product in other developments.

Another area of interest was measuring air leakage to the party wall between the townhome units - specifically to see if any air was leaking through the party-wall detail in the attic space. Guarded blower-door measurements were taken to gather a baseline air leakage between units; however, the measured leakage through the party wall was lower than the accuracy of the measurement equipment. Minor leakage may have occurred between the attic spaces, but this leakage was lower than the noise floor of standard airtightness test equipment and can be assumed to be insignificant in a well-vented attic.

Results from this study are valuable to the contractor and homebuilder audiences. The results suggest small-diameter systems provide better comfort than conventional systems; also, the smaller ductwork is easier to bring into conditioned space. 


\section{Introduction}

This project was created from a partnership between the U.S. Department of Energy's (DOE's) Building America research team IBACOS, Inc. and New Town Builders. New Town Builders, a production homebuilder in the cold-dry climate of Denver, Colorado, is committed to bringing energy efficiency and high performance to its customers. The builder is producing single-family homes and multifamily structures in Denver's Stapleton development. As this project developed, the builder committed to having $100 \%$ of its single-family detached home product meet the DOE Challenge Home National Program Requirements (DOE 2013) in 2014.

IBACOS worked with New Town Builders to evaluate cost-effective design and specification packages to comply with the DOE Challenge Home National Program Requirements for the builder's townhomes being constructed at Stapleton in Denver. The evaluation was intended to support the builder by developing viable strategies to move forward with the Challenge Home program for townhomes and to provide DOE with useful feedback about the attractiveness and challenges of the program to a production builder that produces townhomes. As part of the package development, IBACOS selected space-conditioning systems for evaluation and comparison.

A primary purpose of this project is to evaluate the performance of all-electric spaceconditioning systems with respect to the performance of the builder's standard package of conventional, combined natural gas and electric systems in high-performance townhomes.

Specifically, the research team evaluated small-diameter air-source heat pump spaceconditioning systems - which consist of small air handling units and small-diameter ductwork that are placed within the building's thermal envelope - against the conventional systems. Energy use, system runtime, and measured comfort conditions were compared for installations in low-load ${ }^{2}$ occupied townhome units. The performance characteristics of a multihead ductless mini-split heat pump system were also evaluated and compared.

\subsection{Background}

IBACOS began working with New Town Builders in 2013 to identify and implement a Challenge Home package for the builder's standard product line in the Stapleton community of Denver, Colorado. The builder performed a process of optimization through design and purchasing to arrive at a single-family detached home product that meets Home Energy Rating System (HERS) ratings of $\sim 40$ without photovoltaics and HERS $<10$ with photovoltaics (RESNET 2015). One of IBACOS' objectives was to extend a comparable level of performance to the builder's townhome product.

One issue that New Town Builders has seen in the two- and three-story townhome market, even with units that are built to high-performance standards, is temperature stratification from floor to floor. This has been a result of lower space-conditioning loads, the lower system airflows

\footnotetext{
${ }^{2}$ Low load has generally been accepted as a home with a peak space conditioning energy demand that is less than $10 \mathrm{Btu} / \mathrm{h} / \mathrm{ft}^{2}$ of conditioned floor area (Brown, Thornton, and Widder 2013). The townhomes in this study had peak cooling energy consumption ranging from 11.25 to $12.3 \mathrm{Btu} / \mathrm{h} / \mathrm{ft}^{2}$ or slightly higher than the threshold.
} 
associated with the loads, and ultimately the lack of adequate air mixing that stems from the lower airflows in conventional ducted systems.

New Town Builders desired to address this issue head-on to help develop solutions that would benefit its customers and would help improve townhomes being delivered across the industry.

Previous research conducted by IBACOS on small-diameter systems suggests that those systems may be an effective alternative to conventional systems for bringing ductwork into conditioned space. An early version of the small-diameter system used in this project was tested in an unoccupied lab house in Pittsburgh, Pennsylvania (Poerschke 2016). The ability of this test system to provide comfort was somewhat hampered by inadequate airflow balancing. However, superior air mixing was shown relative to conventionally sized ductwork by computational fluid dynamics simulations.

Conclusions from Rittelmann (2008) indicate that floor-to-floor stratification increases with greater outdoor-to-indoor temperature differences. This is no surprise, because this difference is the driving force in stack effect. For the three-story homes considered in the current study, during the peak outdoor conditions of $90^{\circ} \mathrm{F}$, the stack effect may result in as much as $60 \mathrm{CFM}$ of air moving from the bottom floors to the top floor. This buoyancy pressure must be overcome by the air handling system. Because the small-diameter system operates with a higher static pressure in the supply plenum, it is better suited to overcome the stack effect pressure of tall buildings that is acting as a force to restrain the air from returning down to the return plenum.

\subsection{Overview of the Builder}

New Town Builders is headquartered in Denver, Colorado, and was founded in 1992. The company is a niche production homebuilder, with 130 closings per year in a market dominated by large national builders. It is a leader in building and marketing high-performance, energyefficient homes in the Denver metro area. Its business philosophy includes providing innovative high performance because it is the "right thing to do." At the heart of the New Town Builders business approach are the commitments to continually look for ways to add value and to articulate that value to its customers, understanding that buying a home is primarily an emotional decision.

In recent years, New Town Builders has participated in a series of advanced industry performance verification programs to gain expert third-party verification to help it market the benefits from the high-performance features it builds into its homes. Recent programs have included the U.S. Environmental Protection Agency ENERGY STAR ${ }^{\circledR}$ program (EPA 2015), the TopBuild Home Services' Environments For Living program (TopBuild 2015), the Home Builders Association of Metro Denver (HBA 2015) Built Green Colorado program (Built Green 2015), the DOE Challenge Home program (DOE 2013), and most recently as this project has continued, the DOE Zero Energy Ready Home (ZERH) program (DOE 2015). In each case, New Town Builders sought to be among the first participants in the respective program to continue to set itself apart.

New Town Builders was the national Grand Award Winner among production builders at the DOE Housing Innovation Awards in 2013 and 2014. It also earned the ENERGY STAR Market Leader Award in 2013 and 2014 from the U.S. Environmental Protection Agency. 
New Town Builders continues to seek ways to verify and market home performance. Beyond energy efficiency, the qualities of comfort, indoor environment health, and water conservation are of specific interest to the builder and its customers.

\subsection{Challenge Home Target Specifications}

The IBACOS team used Building Energy Optimization software (BEopt ${ }^{\mathrm{TM}}$ ) Version 2.2.0.1 to evaluate cost optimizations based on the builder's current townhome construction package, options to approach Challenge Home program requirements, true costs, and other local market costs for other BEopt options selected (NREL 2014).

Table 1 tabulates for one townhome floor plan (Plan 1120) the results of the preliminary effort to identify package options to reach Challenge Home requirements. The various options differ in the type of air distribution system proposed. Note that Option 3, including ducted mini-splits, did not meet Challenge Home criteria in the preliminary effort.

As this project continued, the builder partner decided that the time was not right to introduce a Challenge Home townhome product into the Stapleton development. Thus, the packages identified in Table 1 were not developed further. Changing production approach midstream at this location was deemed to be disruptive and was no longer the builder's goal. Two triplex buildings of townhomes were constructed to standards meeting ENERGY STAR Version 3.0 to compare the various space-conditioning approaches. 
Table 1. Results of Preliminary Challenge Home Specification Analysis for Floor Plan 1120

\begin{tabular}{|c|c|c|c|}
\hline Specifications & Option 1 & Option 2 & Option $3^{\mathrm{a}}$ \\
\hline Slab Floor Properties & R-10, 1.5-in. thick; carpeting & R-10, 1.5-in. thick; carpeting & $\begin{array}{l}\text { R-10, } 1.5 \text {-in. thick; } \\
\text { carpeting }\end{array}$ \\
\hline Above-Grade Exterior Walls & $2 \times 6 ;$ R-23 blown fiberglass & $2 \times 6 ; \mathrm{R}-23$ blown fiberglass & $\begin{array}{l}2 \times 6 ; \text { R-23 blown } \\
\text { fiberglass }\end{array}$ \\
\hline Roof & $\begin{array}{c}\text { R-60 attic blown insulation flat; } \\
\text { R-50 attic blown insulation flat } \\
\text { edge }\end{array}$ & $\begin{array}{c}\text { R-60 attic blown insulation flat; } \\
\text { R-50 attic blown insulation flat } \\
\text { edge }\end{array}$ & $\begin{array}{l}\text { R-60 attic blown insulation } \\
\text { flat; } \\
\text { R-50 attic blown insulation } \\
\text { flat edge }\end{array}$ \\
\hline Windows & $\begin{array}{l}\text { Vinyl; double glazed; low-E; } \\
\qquad U=0.27 \text {; SHGC }=0.28\end{array}$ & $\begin{array}{l}\text { Vinyl; double glazed; low-E; } \\
\qquad \mathrm{U}=0.27 \text {; SHGC }=0.29\end{array}$ & $\begin{array}{l}\text { Vinyl; double glazed; low- } \\
\mathrm{E} ; \mathrm{U}=0.27 ; \mathrm{SHGC}=0.30\end{array}$ \\
\hline Building Airtightness & $\mathrm{ACH}(50)=0.25$ & $\mathrm{ACH}(50)=0.25$ & $\mathrm{ACH}(50)=0.25$ \\
\hline Mechanical Ventilation & Exhaust only & Exhaust only & Exhaust only \\
\hline Air Distribution Strategy & $\begin{array}{l}\text { Ducted/ductless mini-split } \\
\text { system }\end{array}$ & Ductless mini-split & Ducted mini-split \\
\hline $\begin{array}{l}\text { Ducted } \\
\text { Heating }\end{array}$ & 7.20 HSPF & N/A & 7.20 HSPF \\
\hline $\begin{array}{l}\text { Ducted } \\
\text { Cooling }\end{array}$ & 12.5 SEER & N/A & 12.5 SEER \\
\hline Ductless Heating & 9.1 HSPF & 9.1 HSPF & $\mathrm{N} / \mathrm{A}$ \\
\hline Ductless Cooling & 20.0 SEER & 20.0 SEER & N/A \\
\hline Ductwork & Inside conditioned space & Inside conditioned space & Inside conditioned space \\
\hline Water Heater & $\begin{array}{c}\text { Navien energy factor }=0.97 ; \\
\text { natural gas; tankless }\end{array}$ & $\begin{array}{c}\text { Navien energy factor }=0.97 ; \\
\text { natural gas; tankless }\end{array}$ & $\begin{array}{c}\text { Navien energy factor }= \\
0.97 \text {; natural gas; tankless }\end{array}$ \\
\hline HERS Index (Worst Case) & 65 & 59 & $66^{*}$ \\
\hline $\begin{array}{l}\text { Challenge Home Target } \\
\text { Index }\end{array}$ & 65 & 63 & 64 \\
\hline
\end{tabular}

${ }^{\mathrm{a}}$ This option did not result in a package that met Challenge Home requirements.

$\mathrm{ACH}(50)$ is air changes per hour at 50 Pascals. HSPF is heating seasonal performance factor. N/A is not applicable. SEER is seasonal energy efficiency ratio. SHGC is solar heat gain coefficient. 


\section{Mathematical and Modeling Methods}

\subsection{Research Questions}

The following research questions will be answered by this project:

1. What are the differences in performance of a small-diameter duct system compared to a conventionally sized duct system as judged by energy consumption and comfort? Specifically, the following metrics will be used:

- Air Conditioning Contractors of America (ACCA) Manual RS (Rutkowski 1997)

○ ASHRAE Standard 55 (ASHRAE 2013)

- System runtime

○ Energy consumption by each unit

2. What is the measurable air leakage to the party wall between units, to the attic space, or to the garage?

3. How does building to DOE Challenge Home standards impact the builder's business?

\subsection{Comfort Metrics}

The research team used two metrics to judge the comfort in each townhome: spatial uniformity and temporal uniformity. According to ACCA Manual RS, the room-to-thermostat temperature variation in occupied space may not exceed $2^{\circ} \mathrm{F}$ during the heating season and $3^{\circ} \mathrm{F}$ during the cooling season (Rutkowski 1997). Also, the room-to-room temperature difference should be less than $4^{\circ} \mathrm{F}\left(2^{\circ} \mathrm{F}\right.$ average $)$ in the heating season and less than $6^{\circ} \mathrm{F}\left(4^{\circ} \mathrm{F}\right.$ average $)$ in the cooling season. This is called room-to-room uniformity, or room-to-room $\Delta \mathrm{T}$ in this report, and is calculated as follows: For each timestamp, the temperature of the coolest room is subtracted from that of the warmest room to yield the room-to-room $\Delta \mathrm{T}$.

ASHRAE Standard 55 (ASHRAE 2013) outlines a range of acceptable temperature changes over time, as specified in Table 2. If the temperature in a particular space changes more than the maximum value in each time interval, this is deemed to be a comfort concern. If a temperature change is caused by the heating, ventilating, and air-conditioning (HVAC) system operation, it is deemed a "ramp" failure.

Table 2. ASHRAE Standard 55 Temperature Changes over Time

\begin{tabular}{c|c|c|c|c|c}
\hline Time (min.) & $\mathbf{1 5}$ & $\mathbf{3 0}$ & $\mathbf{6 0}$ & $\mathbf{1 2 0}$ & $\mathbf{2 4 0}$ \\
Temperature $\Delta \mathrm{T}\left({ }^{\circ} \mathrm{F}\right)$ & $2^{\circ} \mathrm{F}$ & $3^{\circ} \mathrm{F}$ & $4^{\circ} \mathrm{F}$ & $5^{\circ} \mathrm{F}$ & $6^{\circ} \mathrm{F}$ \\
\hline
\end{tabular}

A diagram of ACCA and ASHRAE comfort failure modes is presented in Figure 1. As shown in this diagram, the top floor is failing thermostat-to-room uniformity most of the time. During the peak temperature in the afternoon, the room-to-room uniformity is beyond the $6^{\circ} \mathrm{F}$ boundary. A rapid decline in the temperature of the top floor may be deemed uncomfortable, according to ASHRAE Standard 55 (ASHRAE 2013). 


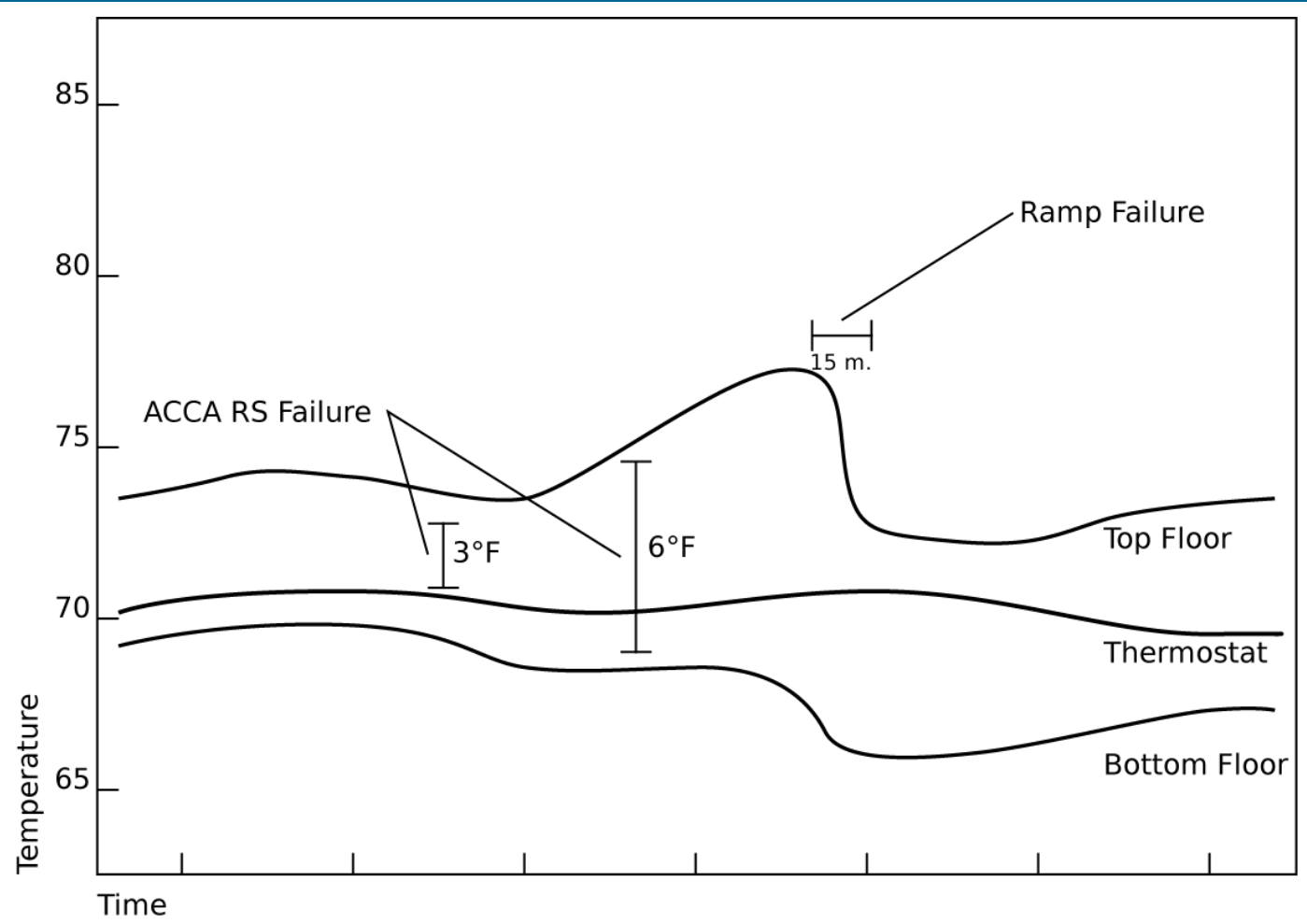

Figure 1. Diagram showing ACCA Manual RS and drift/ramp failures

Previous work by IBACOS (Poerschke 2016) showed that in 37 new homes in a hot-humid climate, occupants used a wide distribution of set points, even among homes in the same community. Performing a complete predicted mean vote calculation may not provide useful insight and could introduce a number of assumptions (e.g., air speed, metabolic rate, clothing level). Also, by choosing room-to-room uniformity as the metric, it is not likely to be influenced by the set point or changes in the set point. For this reason, the team decided that thermal uniformity metrics provide better performance insight, especially when comparing multiple occupied test houses.

The team performed a propagation of error analysis to determine the likelihood of drawing an incorrect conclusion on whether a room passed the ACCA standard because of sensor error. This analysis was highly dependent on the room-to-thermostat temperature difference distribution, in that the closer and more frequent a measurement was to the $\pm 2^{\circ} \mathrm{F}$ threshold, the greater the likelihood of drawing an incorrect conclusion. To perform the error analysis, the team used a Monte Carlo method for determining the likelihood of drawing an incorrect conclusion. For this method, IBACOS made the following assumptions:

- Sensor error is random and normally distributed; listed inaccuracies indicate the $95 \%$ interval (two standard deviations).

- Measurement uncertainty is independent between sensors.

- Room air temperature to thermostat temperature is normally distributed; the room air temperature is centered at the thermostat temperature. 
An analysis of previously measured data from a new construction unoccupied test house in Pittsburgh, Pennsylvania (Poerschke and Stecher 2014), indicated that the typical room-tothermostat temperature difference followed a normal distribution; standard deviations ranged from $1.7^{\circ} \mathrm{F}$ to $2.4^{\circ} \mathrm{F}$.

Using R software, ${ }^{3}$ the team took 100,000 normally distributed samples of possible sensor measurements and error and then calculated the average failure rate in correctly determining the pass rate of a room according to the ACCA Manual RS standard (Rutkowski 1997). Figure 2 indicates these probabilities, given a sensor error of $0.38^{\circ} \mathrm{F}$. Based on Figure 2, the team concluded that there is close to a $95 \%$ confidence in correctly determining failure rates with the data logger. To create this figure, the team ran the simulation for a number of discrete values for room-to-thermostat standard deviation and created a curve based on these results.

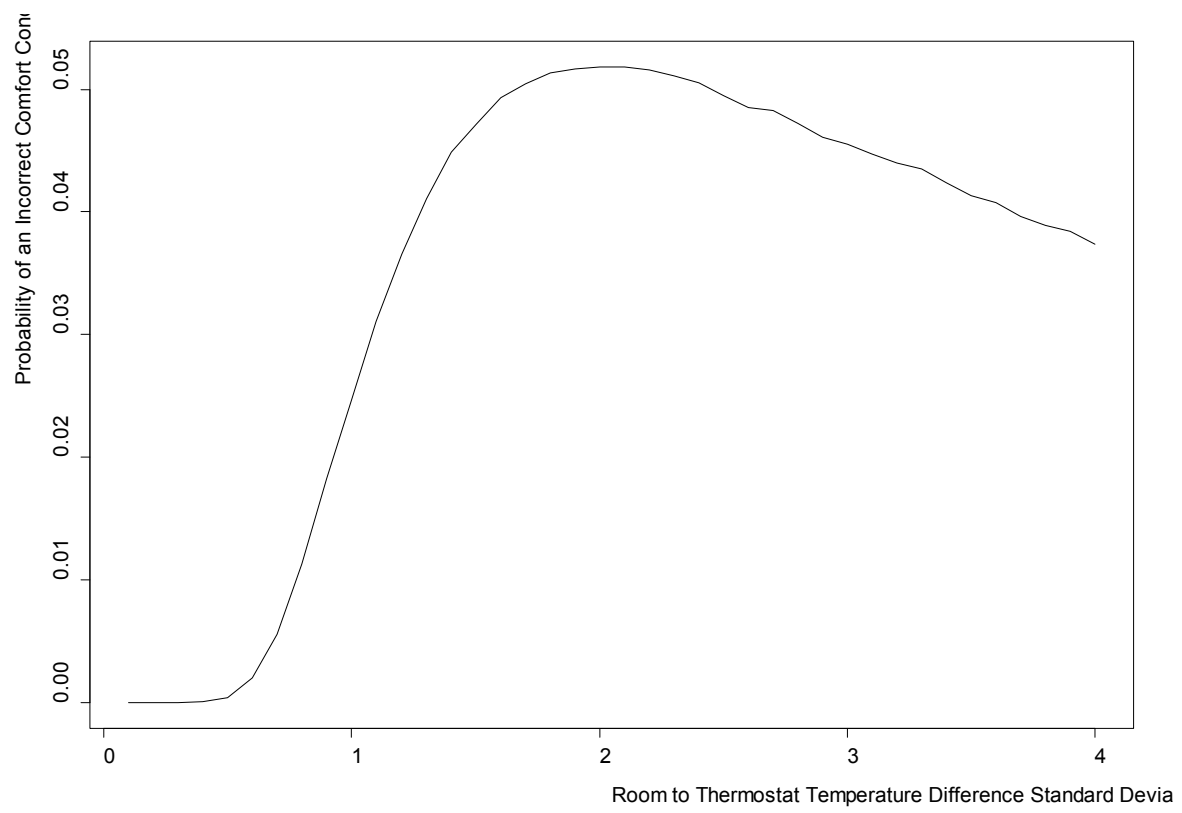

Figure 2. Probability of drawing an incorrect conclusion in the ACCA analysis for sensors with an error of $0.38^{\circ} \mathrm{F}$

\footnotetext{
${ }^{3}$ R software. The R Foundation. www.r-project.org/.
} 


\section{Research/Experimental Methods}

\subsection{Occupied Test House Construction}

IBACOS worked with New Town Builders in 2014 to identify and implement a 100\% Challenge Home package for the builder's townhome product line. The builder had already done an internal optimization through design and purchasing to arrive at its current HERS rating of $\sim 40$ for its single-family detached product. Similar results were sought for its townhome product line.

IBACOS planned to complete at least one new construction occupied test townhome project in 2014 to document Challenge Home implementation of $100 \%$ of the builder's product line. IBACOS worked with the builder to select two potential floor plans for the occupied test townhome. Although the test townhome project originally was planned to be completed during the third quarter of 2014, construction delays resulted in the townhome not being completed until the end of the first quarter of 2015. Thus, the team could not collect data during the heating season.

Figure 3 shows a diagram of the Stapleton community where the test townhomes were built.

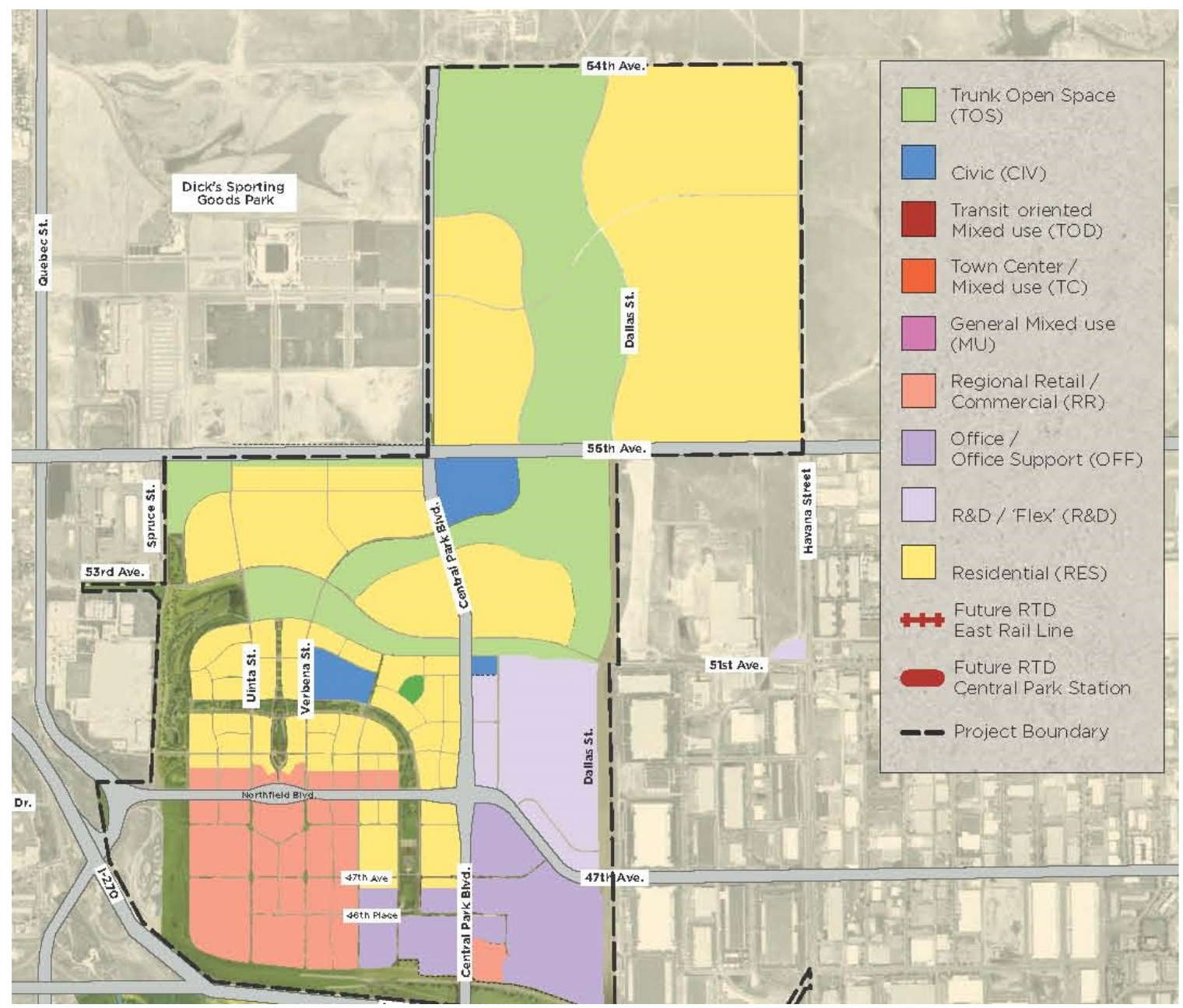

Figure 3. Site map of the Stapleton community 
IBACOS was exploring new space-conditioning options, including a small-diameter system and a ductless mini-split heat pump system. The townhouse complex consisted of groupings of three townhome units side by side; each had three levels and an integral garage. Figure 4 shows an orthographic rendering of the townhome unit's floor plan.
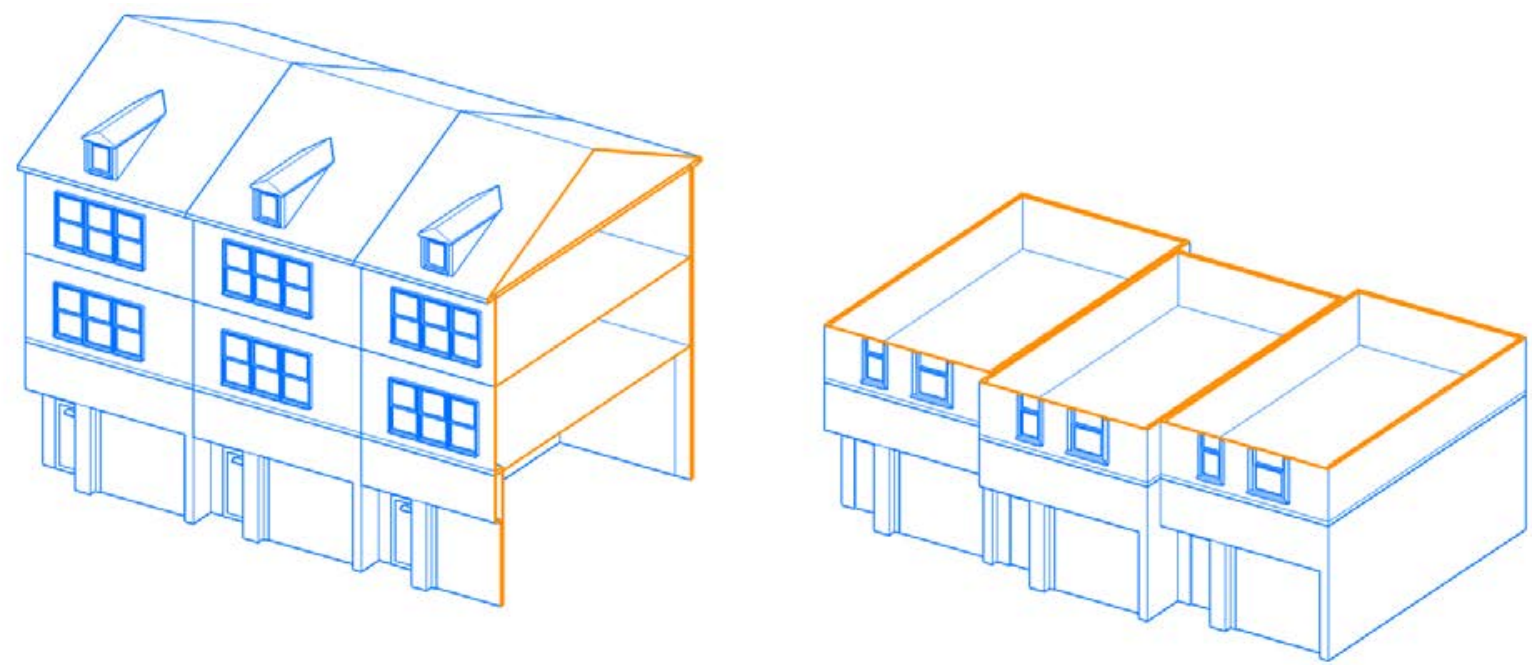

Figure 4. Orthographic drawing of the test homes (not to scale)

Two townhomes were conditioned with a Unico small-diameter central system; one home was conditioned with a Unico mini-split heat pump system. As a control, the standard system used the builder's conventionally sized heating and cooling equipment in three units. Figure 5 is a diagram of the test home arrangement.

Unico

Small Diameter MSHP

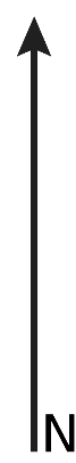

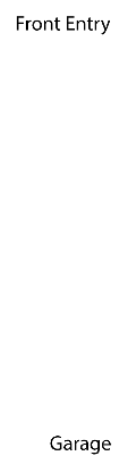

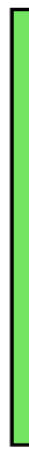

A3

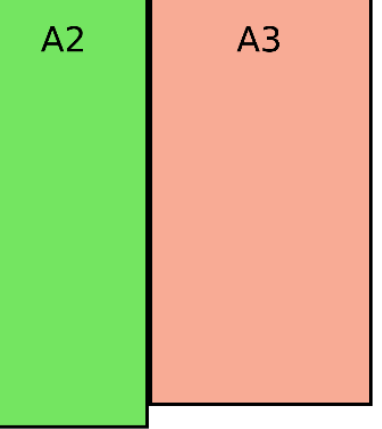

Standard

Central DX

Figure 5. Plan view drawing of the test home arrangement 
Much of the glazing was located on the southern and northern faces of each townhome. Figure 6 and Figure 7 show front and back views of the homes, respectively. Windows and other architectural features can be seen. Some shading devices and overhangs can be seen, but they serve no function because they are on the northern face. These townhomes have no shading devices or overhangs on the southern side, which would reduce energy consumption and improve comfort. An opportunity exists to educate builders on correct solar orientation and shading design.

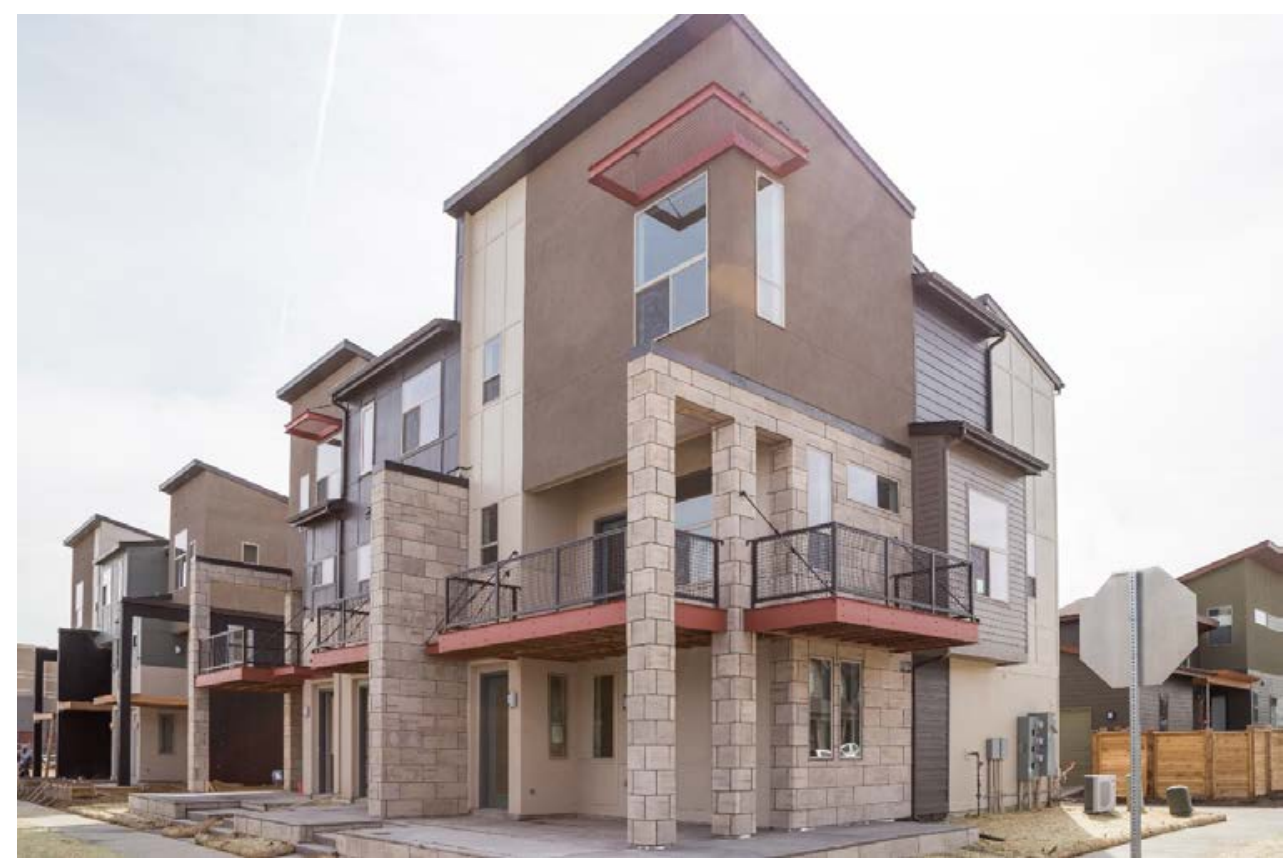

Figure 6. Front elevation showing all six townhomes (doors facing north)

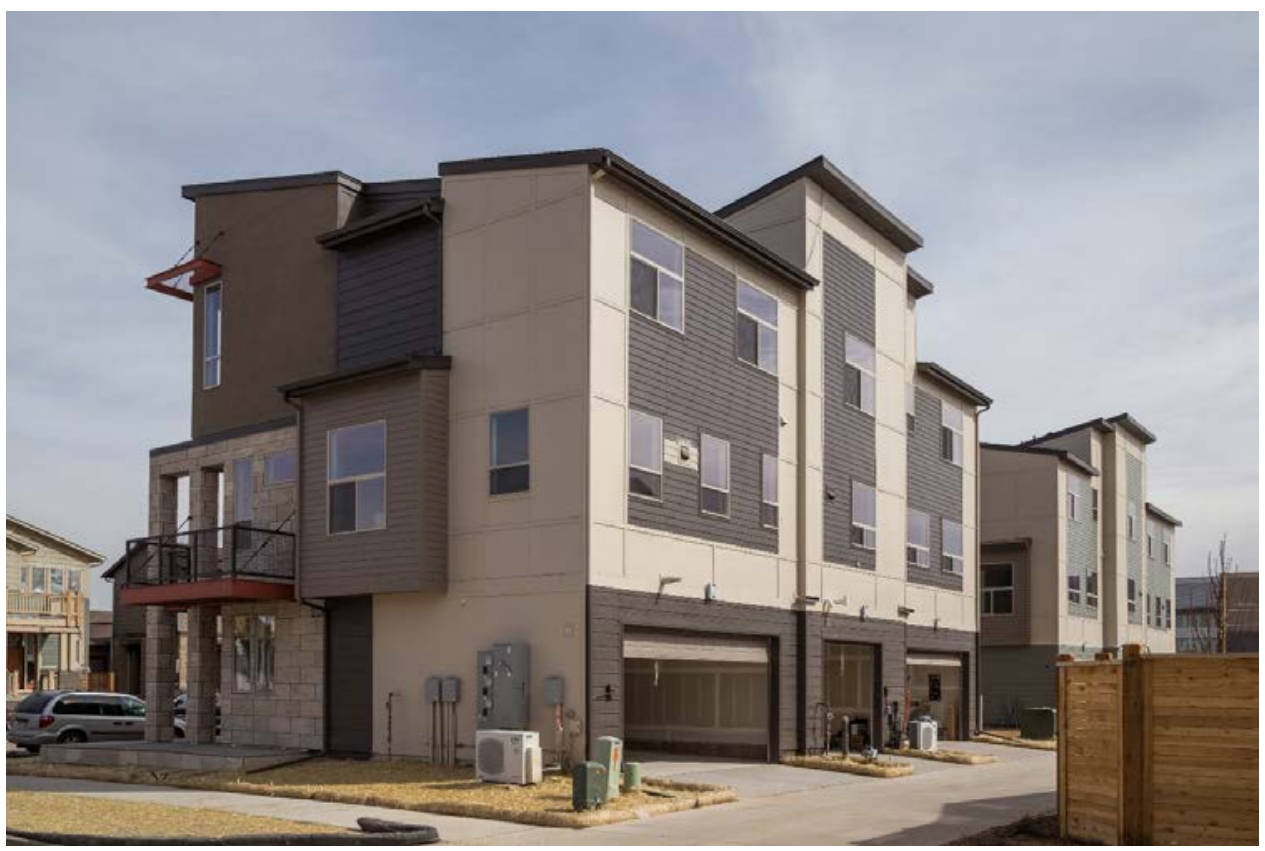

Figure 7. Back elevation showing all six townhomes (garages facing south) 
Ultimately, the builder decided not to implement all aspects of the Challenge Home program. As-built home enclosure specifications are listed in Table 3.

Table 3. Home Enclosure Specifications

\begin{tabular}{|c|c|}
\hline Ceiling Flat & $\mathrm{R}-38$ \\
Sealed Attic & $\mathrm{N} / \mathrm{A}$ \\
\hline Vaulted Ceiling & $\mathrm{N} / \mathrm{A}$ \\
\hline Above-Grade Walls & $\mathrm{R}-23$ \\
\hline Foundation Walls & $\mathrm{N} / \mathrm{A}$ \\
\hline Exposed Floor & $\mathrm{R}-50.4$ \\
Slab & $\mathrm{R}-10$ edge; $\mathrm{R}-0$ under \\
Duct & $\mathrm{R}-4.0$ \\
\hline Window & $\mathrm{U}$-value $=0.310 ; \mathrm{SHGC}=0.300$ \\
\hline
\end{tabular}

Load calculations for system sizing were performed using ACCA Manual J (Rutkowski 2006). Cooling loads ranged from 13,000 to $18,000 \mathrm{Btu} / \mathrm{h}$. Table 4 summarizes the design cooling loads and installed equipment, as well as the rated air leakage for the whole house and ductwork.

Each installed air conditioner was oversized relative to the design cooling load. The standard units (B1, B2, and B3) were sized according to the contractor's standard practice. Although it may have consequences in terms of efficiency and comfort, HVAC contractors commonly oversize equipment by $1 / 2$ ton or more because they believe this will provide a more satisfactory experience for the homeowner.

The compressor for the small-diameter systems (A1 and A2) was variable capacity, and the compressor speed would vary with changes in outdoor temperature.

In the case of the ductless heat pump system (A3), a 36-kBtu/h outdoor unit was installed for several reasons. Primarily, this home did not have a backup heat source, and the contractor wanted to ensure that the system could deliver sufficient heat during the coldest periods. The ductless heat pump system can also modulate the outdoor and indoor unit speeds to match building load; as such, oversizing is a lesser concern because the compressor can run at a lower speed most of the time.

The research may have been impacted by the oversized air conditioners. However, this represents real-world conditions that are often seen in the production home setting. The smalldiameter system has the advantage of being a variable-capacity compressor, which is a benefit given that contractors tend to oversize equipment.

The builder's standard duct layout comprises a mixture of ceiling and floor registers, most of which were placed in the floor; the foyer and second-floor bathroom have ceiling registers. Conventional registers of the following sizes were used: $10 \times 4$ in., $14 \times 6$ in., and $10 \times 2$ in. 
Table 4. Calculated Load and Installed Equipment and Rated Leakage

\begin{tabular}{|c|c|c|c|c|c|c|}
\hline & A1 & A2 & A3 & B1 & B2 & B3 \\
\hline $\begin{array}{l}\text { Design Cooling } \\
\text { Load (kBtu/h) }\end{array}$ & 16 & 13 & 18 & 16 & 13 & 18 \\
\hline $\begin{array}{c}\text { Air Conditioner } \\
\text { Rated Capacity } \\
\quad(\mathrm{kBtu} / \mathrm{h})\end{array}$ & 24 & 24 & 36 & 24 & 18 & 24 \\
\hline $\begin{array}{l}\text { Outdoor Unit } \\
\text { Model }\end{array}$ & IS24G065 & IS24G065 & IS36G110 & CA13NA24 & CA13NA18 & CA13NA24 \\
\hline $\begin{array}{l}\text { Air Handling } \\
\text { Unit Model }\end{array}$ & M2430BL1-EA2 & M2430BL1-EA2 & IS12MPA & 59SC2C040S17 & 59SC2C040S17 & $59 \mathrm{SC} 2 \mathrm{C} 040 \mathrm{~S} 17$ \\
\hline $\begin{array}{l}\text { Ductwork } \\
\text { Location }\end{array}$ & $\begin{array}{l}\text { Conditioned } \\
\text { space }\end{array}$ & $\begin{array}{l}\text { Conditioned } \\
\text { space }\end{array}$ & $\begin{array}{l}\text { Conditioned } \\
\text { space }\end{array}$ & $\begin{array}{l}\text { Conditioned } \\
\text { space }\end{array}$ & $\begin{array}{l}\text { Conditioned } \\
\text { space }\end{array}$ & $\begin{array}{c}\text { Conditioned } \\
\text { space }\end{array}$ \\
\hline $\begin{array}{l}\text { Air Handling } \\
\text { Unit Location }\end{array}$ & Second floor & Second floor & High wall fan coil & First floor & First floor & First floor \\
\hline $\begin{array}{l}\text { Building } \\
\text { Measured } \\
\text { Air Leakage } \\
\text { (ACH 50) }\end{array}$ & 2.97 & 3.49 & 3.98 & 2.15 & 2.73 & 3.18 \\
\hline $\begin{array}{c}\text { Building } \\
\text { Measured Air } \\
\text { Leakage } \\
\text { (CFM 50) }\end{array}$ & 857 & 750 & 993 & 632 & 585 & 792 \\
\hline $\begin{array}{c}\text { Ductwork } \\
\text { Measured Air } \\
\text { Leakage } \\
\text { (CFM@25 Pa) }\end{array}$ & 54 & 47 & N/A & 5 & 5 & $\mathrm{a}$ \\
\hline Floor Area & $1,300 \mathrm{ft}^{2}$ & $1,100 \mathrm{ft}^{2}$ & $1,600 \mathrm{ft}^{2}$ & $1,300 \mathrm{ft}^{2}$ & $1,100 \mathrm{ft}^{2}$ & $1,600 \mathrm{ft}^{2}$ \\
\hline
\end{tabular}

${ }^{a}$ Data were not available from the rater for this case. 
The small-diameter system comprised a trunk-and-branch system with a mixture of ceiling, floor, and high sidewall registers, most of which were high sidewall, 2.5-in. round. Several 2-in. floor registers were used, and two slot-type registers were used in each townhome. Figure 8 shows an example of the small-diameter ductwork trunk-and-branch arrangement on the top floor of one townhome. With the small-diameter system, bends in the ductwork are used to restrict airflow for short branches and aid in balancing the system. Also, because the branch duct material has sound-attenuating properties, the manufacturer suggests a minimum branch duct length to reduce noise levels at the supply register. Figure 9 shows the small-diameter air handling unit in the middle floor of another townhome.

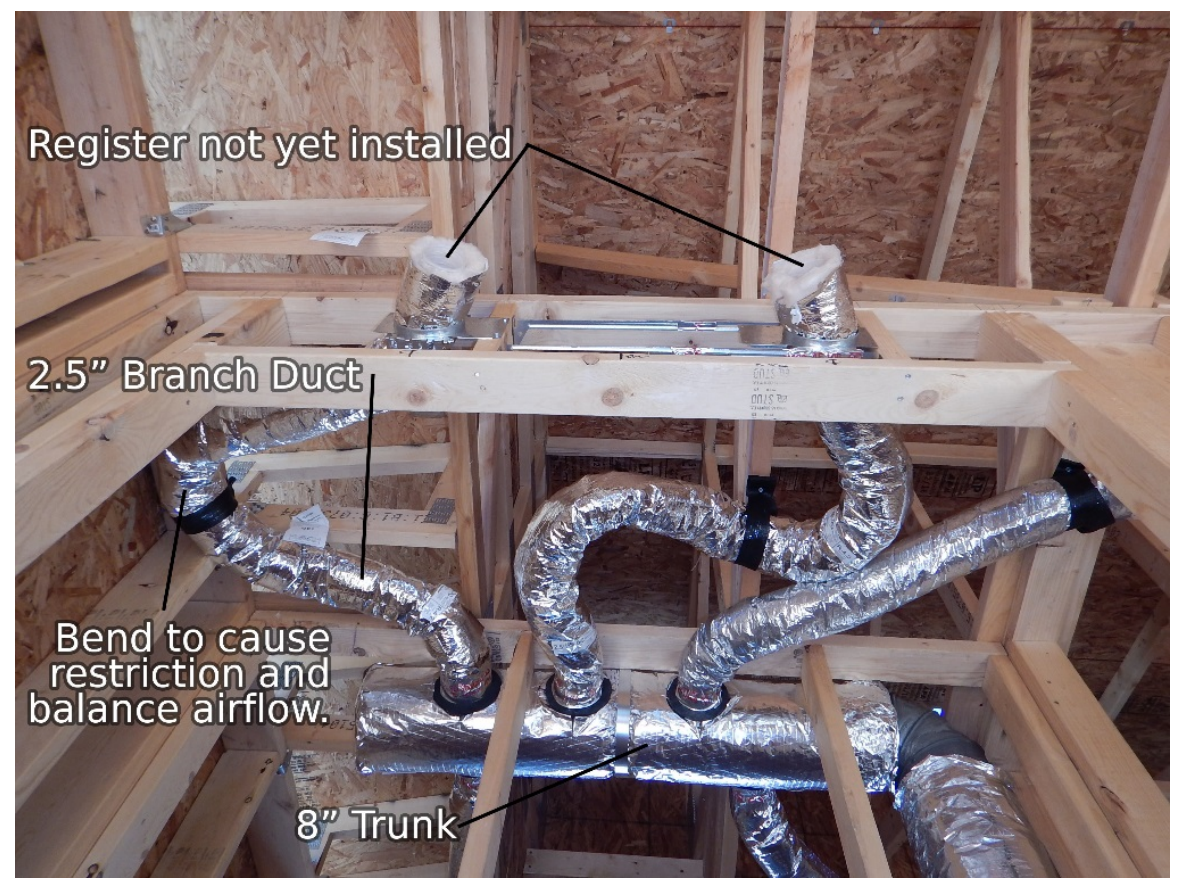

Figure 8. Small-diameter trunk-and-branch plenum on the third floor of Home A1 


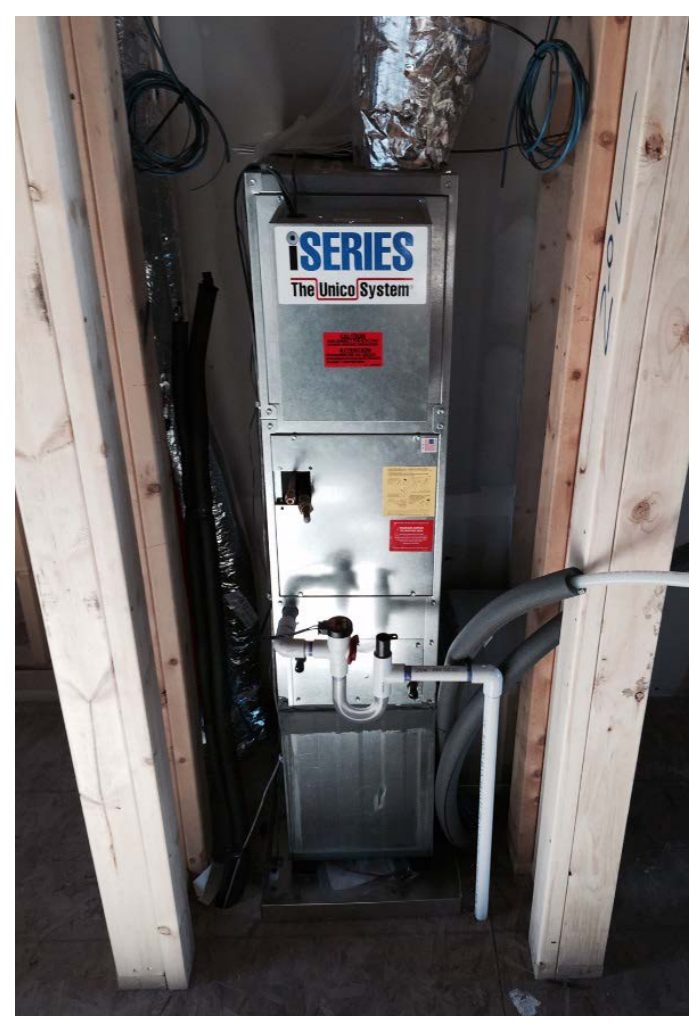

Figure 9. Small-diameter upflow air handling unit on the second floor of Home A2

The measured ductwork air leakage for the small-diameter system (A1 and A2) appears to be significantly higher than that for the builder's standard system. There are several possible reasons for this. The small-diameter ductwork uses flexible ductwork for all branch runs. At the boot connection where the smaller branch connects to the trunk is a foam seal and no mastic. Further, the flexible duct material for the branch runouts is made of a porous fabric-like material designed to dampen noise. This material will allow air to pass through to the exterior insulation material, which is the final air seal. Given this configuration, it is more difficult to air seal the small-diameter ductwork.

The sheet metal ductwork used in the standard system was sealed with mastic at each joint, and the measured results show much lower duct leakage. Figure 10 shows the mastic sealant and a register balancing damper. 


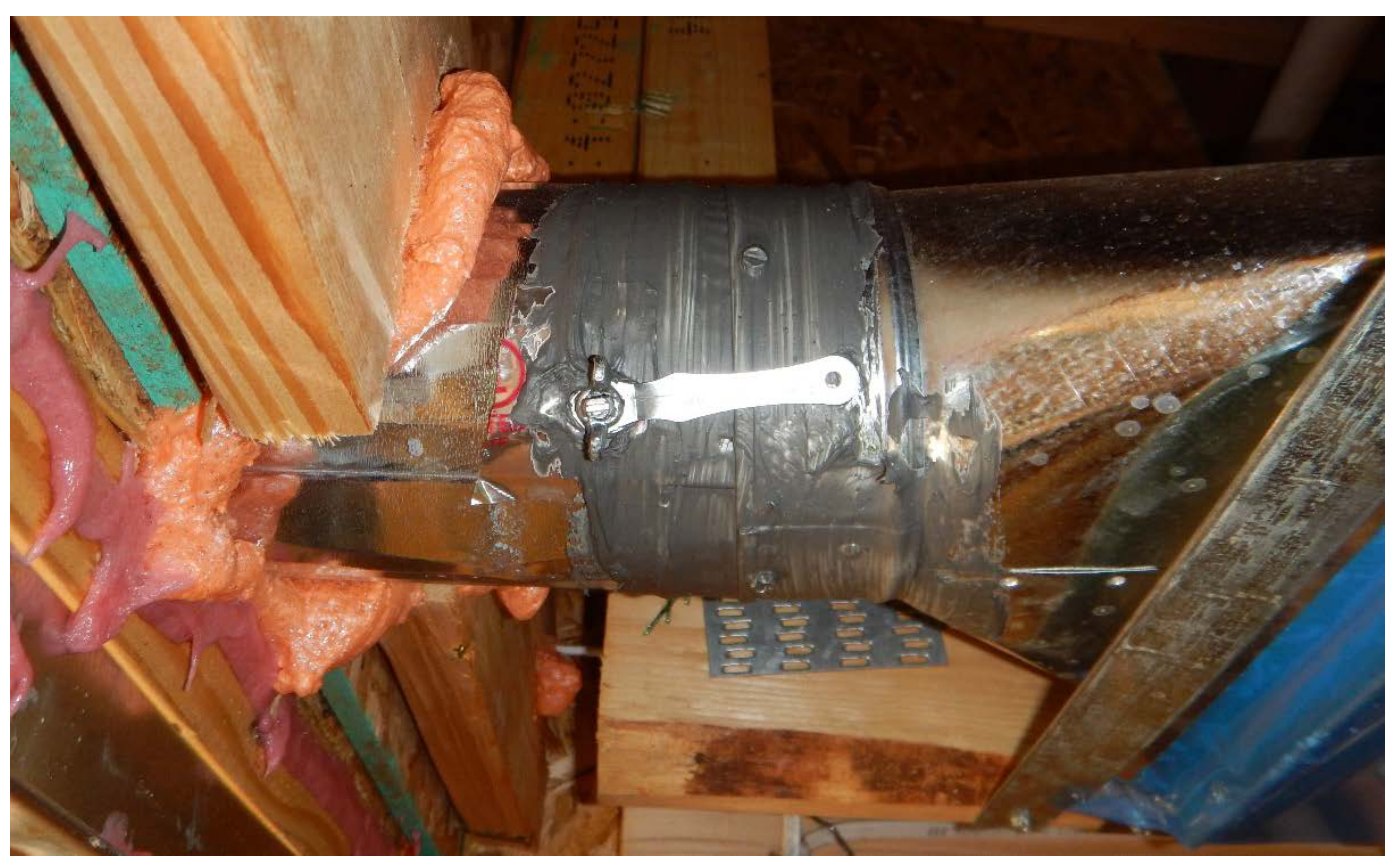

Figure 10. Register for the builder's standard system, showing a balancing damper and mastic

\subsection{Short-Term Monitoring Equipment}

Standard blower door test equipment was used to perform a blower door air leakage test on each townhome unit, as well as a guarded test in which multiple units were depressurized simultaneously. IBACOS worked with a local HERS rater to perform these additional tests simultaneously with the standard HERS rating procedures. The published accuracy of the blower door fan is $3 \%$, and the accuracy of the pressure gauge is $1 \%$.

Ambient conditions for the blower door test included an air temperature of $62^{\circ} \mathrm{F}$, relative humidity of $22 \%$, and wind speeds of 50 to $350 \mathrm{fpm}$ ( 0.6 to $4 \mathrm{mph}$ ), with gusts up to $2,000 \mathrm{fpm}$ $(22.8 \mathrm{mph})$. The occasionally blustery conditions increased the uncertainty in measurement.

One goal of the testing was to understand the interaction between the house and the vented attic space, specifically if there was any interaction between the party walls of each attic space. To measure this interaction, rubber tubing was connected to one end of a differential pressure gauge and inserted into the attic through a gap around the bathroom ventilation fan. With the gauge in the living space, the pressure differential to the attic could be determined. Windy conditions and the nature of the vented attic on a three-story building meant that pressure differences between the attic and the living space showed significant fluctuation. Attempts to determine any change in pressure when adjacent units were connected showed no measurable difference, indicating that any air leakage pathways between the two unvented attics were negligible relative to the magnitude of air leakage from the attic to the outside.

\subsection{Long-Term Monitoring Equipment}

Table 5 lists the equipment, including sensors, used to conduct this research. Temperature and humidity sensors were placed in each major room with at least one sensor per floor. Sensors were housed in small, commercially available thermostat enclosures, as shown in Figure 11, and were situated approximately 36 to 42 in. above the floor level. Sensors were placed on interior 
partition walls, away from supply registers wherever possible. In some of the bathrooms, the only available wall area was directly below a supply register; data from these sensors were not included in the final analysis. In addition to measuring indoor temperature and humidity, a carbon dioxide sensor was installed in the main living space of each house. This sensor provided the team with an indication of the relative occupancy of each house.

Table 5. Measurements and Equipment

\begin{tabular}{|c|c|c|}
\hline Measurement & Equipment Used & Accuracy \\
\hline $\begin{array}{l}\text { Room Temperature and } \\
\text { Relative Humidity }\end{array}$ & $\begin{array}{l}\text { Thermocouple wire and } \\
\text { Campbell Scientific } 210 \\
\text { relative humidity probe (10) }\end{array}$ & $\begin{array}{c}\text { Temperature } 0.1^{\circ} \mathrm{C} \text { and relative } \\
\text { humidity } 25^{\circ} \mathrm{C}: \pm 3 \%\end{array}$ \\
\hline Electric Energy & $\begin{array}{l}\text { Continental Controls Systems } \\
\text { Modbus Wattnode and current } \\
\text { transducers }\end{array}$ & $0.5 \%$ nominal \\
\hline Outdoor Weather & $\begin{array}{l}\text { Campbell Scientific WXT520 } \\
\text { and LI-COR Pyranometer }\end{array}$ & $\begin{array}{c}\text { Temperature } 0.3^{\circ} \mathrm{C} \text { and relative } \\
\text { humidity } 0 \% \text { to } 90 \%: \pm 3 \%\end{array}$ \\
\hline Carbon Dioxide & $\begin{array}{l}\text { tSense carbon dioxide } \\
\text { transmitter }\end{array}$ & $\pm 3 \%$ \\
\hline \multicolumn{3}{|c|}{ Short-Term Testing } \\
\hline Electrical Measurements & $\begin{array}{l}\text { True root mean square clamp- } \\
\quad \text { on meter (e.g., Fluke) }\end{array}$ & N/A \\
\hline $\begin{array}{l}\text { Temperature } \\
\text { Measurements }\end{array}$ & $\begin{array}{l}\text { Humidity and temperature } \\
\text { indicator and probe } \\
\text { (Vaisala or equal) }\end{array}$ & N/A \\
\hline $\begin{array}{c}\text { Building Airtightness } \\
\text { Test }\end{array}$ & $\begin{array}{l}\text { Minneapolis Blower Door } \\
\text { or equivalent device }\end{array}$ & N/A \\
\hline $\begin{array}{c}\text { Data Logger Equipment } \\
\text { Data Logger } \\
\text { Multiplexer }\end{array}$ & $\begin{array}{c}\text { Campbell Scientific CR1000 } \\
\text { Campbell Scientific AM16/32 }\end{array}$ & \\
\hline
\end{tabular}




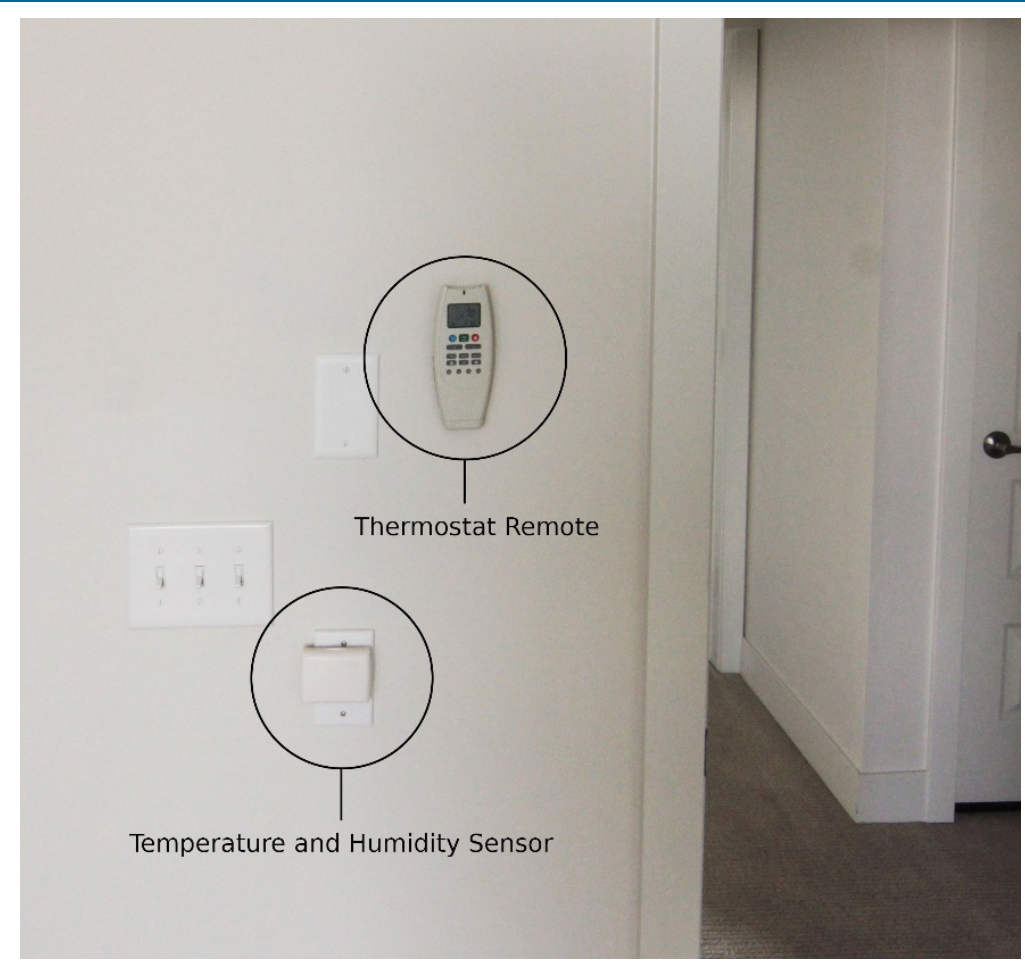

Figure 11. Room sensor and thermostat

All sensors for each building were wired into a central data logger. One data logger was installed in the garage of the center unit in each of the two buildings; an analog measurement multiplexer served each home. A total of two data loggers and six multiplexers were installed, corresponding to two buildings and six townhome units.

Electric power measurements were taken using Continental Controls Systems Modbus Wattnodes, which allowed the team to poll many aspects of the electrical loads in real time, including electric power, voltage, and power factor. The Modbus Wattnodes were wired using a combination of star and bus network topology using the RS-485 physical layer. A single line diagram of the installed system is shown in Figure 12. Generally, RS-485 is designed to be used as a bus-type network, and configuring it as a star network can result in signal reflections that impede communications. However, because the relative cable lengths were short (less than $50 \mathrm{ft}$ ), this topology proved to be reliable. 


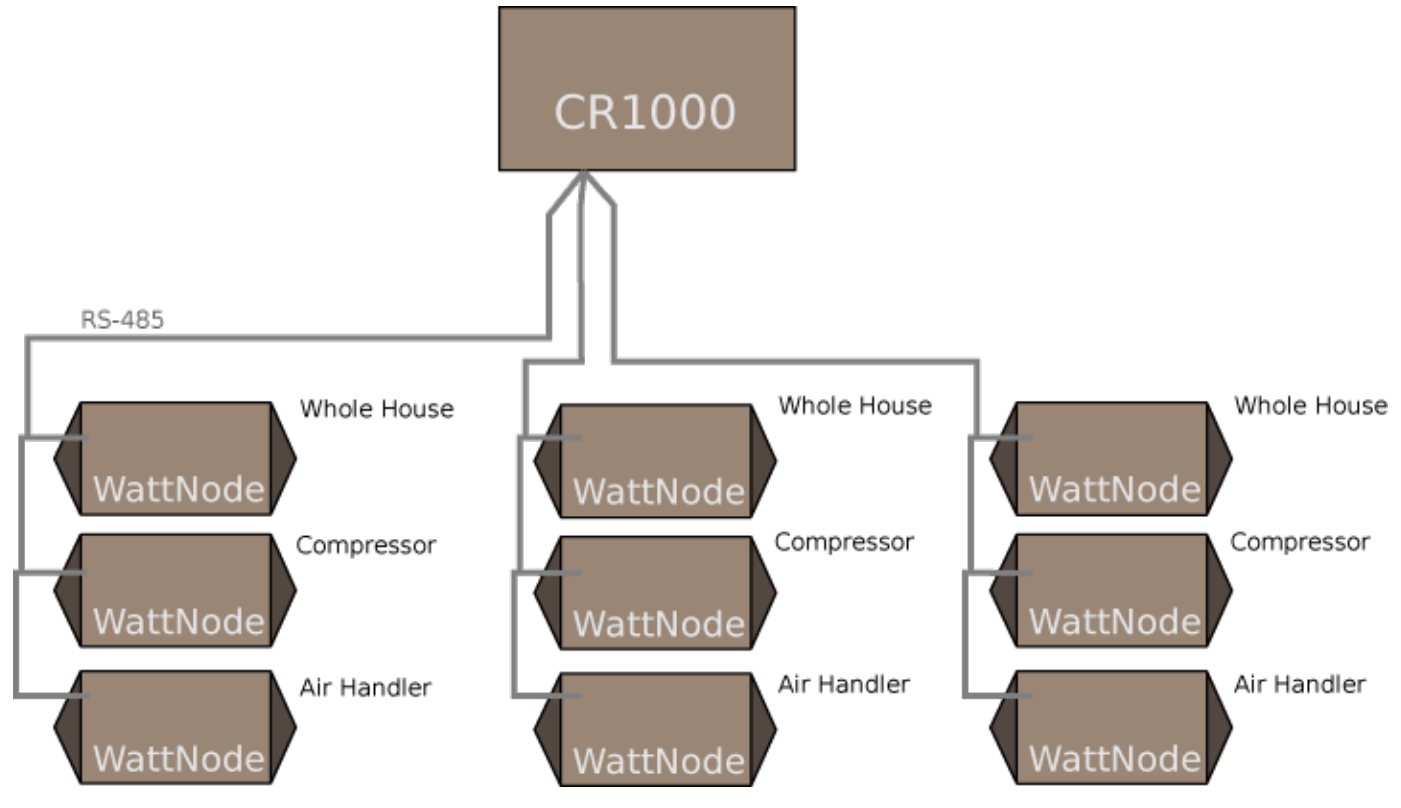

Figure 12. Modbus network topology

Weather data for the site were collected from a multisensor external weather station. This instrument was mounted under the eave of Home A2 and extended $2 \mathrm{ft}$ from the overhang, as shown in Figure 13. Specific measurements included air temperature, humidity, barometric pressure, wind speed and direction, and rainfall. A pyranometer was installed to measure global horizontal irradiance from the sun.

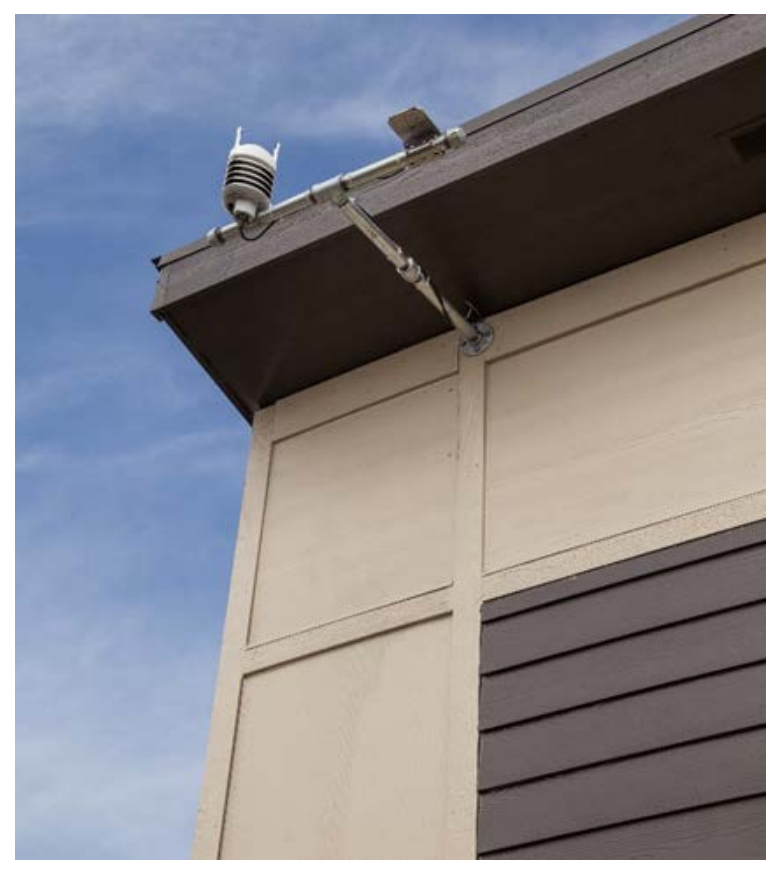

Figure 13. Weather station 
The data collection system was installed in March 2015. Because of an issue with the code inspection, the system had to be removed and rewired before data collection could begin.

Commissioning issues as a result of this removal resulted in various data accuracy concerns until the system was verified in mid-July 2015. Because of the piecemeal accuracy of data before July 2015, all data presented in this report were collected after July 2015. 


\section{Results and Discussion}

Results from the data collection are presented in this section. Analysis focused on two main areas: comfort performance and energy performance. Because the home conditioned with the ductless heat pump system (Home A3) was unoccupied during the test period, data from this system were omitted at times. Furthermore, the top-floor heat pumps were reset to an elevated set point, which artificially skewed the floor-to-floor uniformity.

Data from a selected 9-day period are analyzed in this report. The team chose Aug. 15 through Aug. 23, 2015, because of its variety of hot and cool weather. Outdoor temperature measurements from the weather station are plotted in Figure 14, and solar irradiance measurements are plotted in Figure 15. Typical weather conditions were sunny or partly sunny.

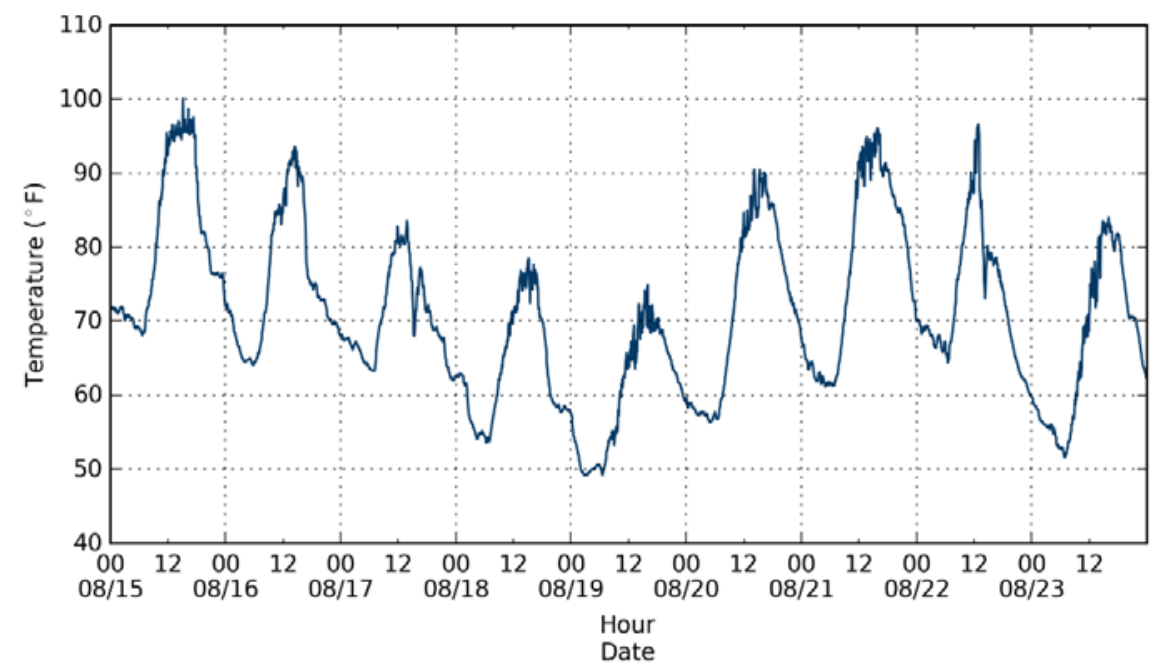

Figure 14. Outdoor temperature measurements at the test site

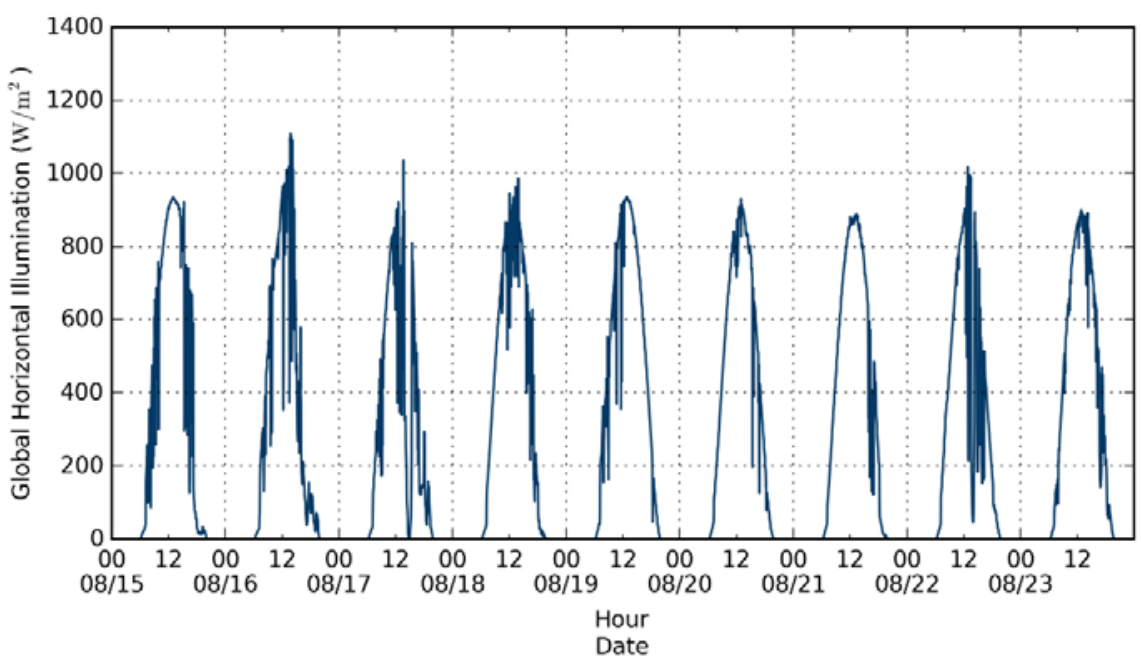

Figure 15. Outdoor solar irradiance at the test site 
The team plotted carbon dioxide measurements taken in the main living space of each house, as shown in Figure 16. Although not an exact indicator of the level of occupancy, some conclusions can be drawn. Home A3 was unoccupied for the entire study, and this is apparent in the measured data. The other homes show some periods of being unoccupied and obviously occupied. As a note, each carbon dioxide sensor was not cross-calibrated; therefore, absolute readings may have a bias. Across the board, carbon dioxide measurements near the background level of approximately $400 \mathrm{ppm}$ suggest that the ventilation strategy employed in each unit was effective.

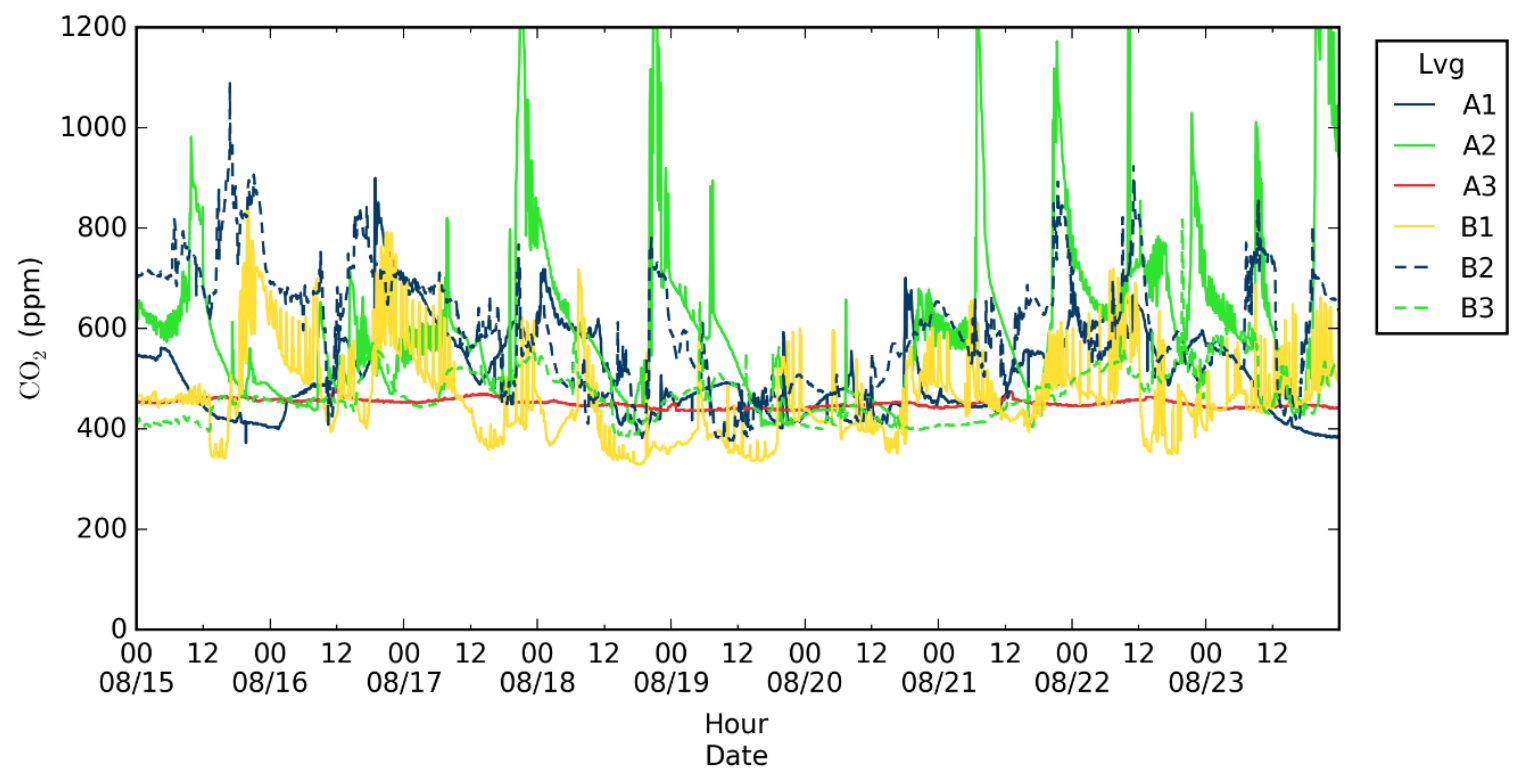

Figure 16. Carbon dioxide levels in the test houses

User-chosen set points can have an impact on the energy used by the cooling system, system runtime, and measured temperature uniformity. Figure 17 shows the hourly average temperature measurement at each thermostat. Notable features included a spike in the set point for Home A1 at the beginning of the analysis period that corresponded to low carbon dioxide values and an assumed period of unoccupancy. Home B2 showed the widest variation of set point, which was reflected in the system runtime and comfort data. Some daily variation was present in each home, suggesting that for some periods, at least, all the occupants were changing the set point. 


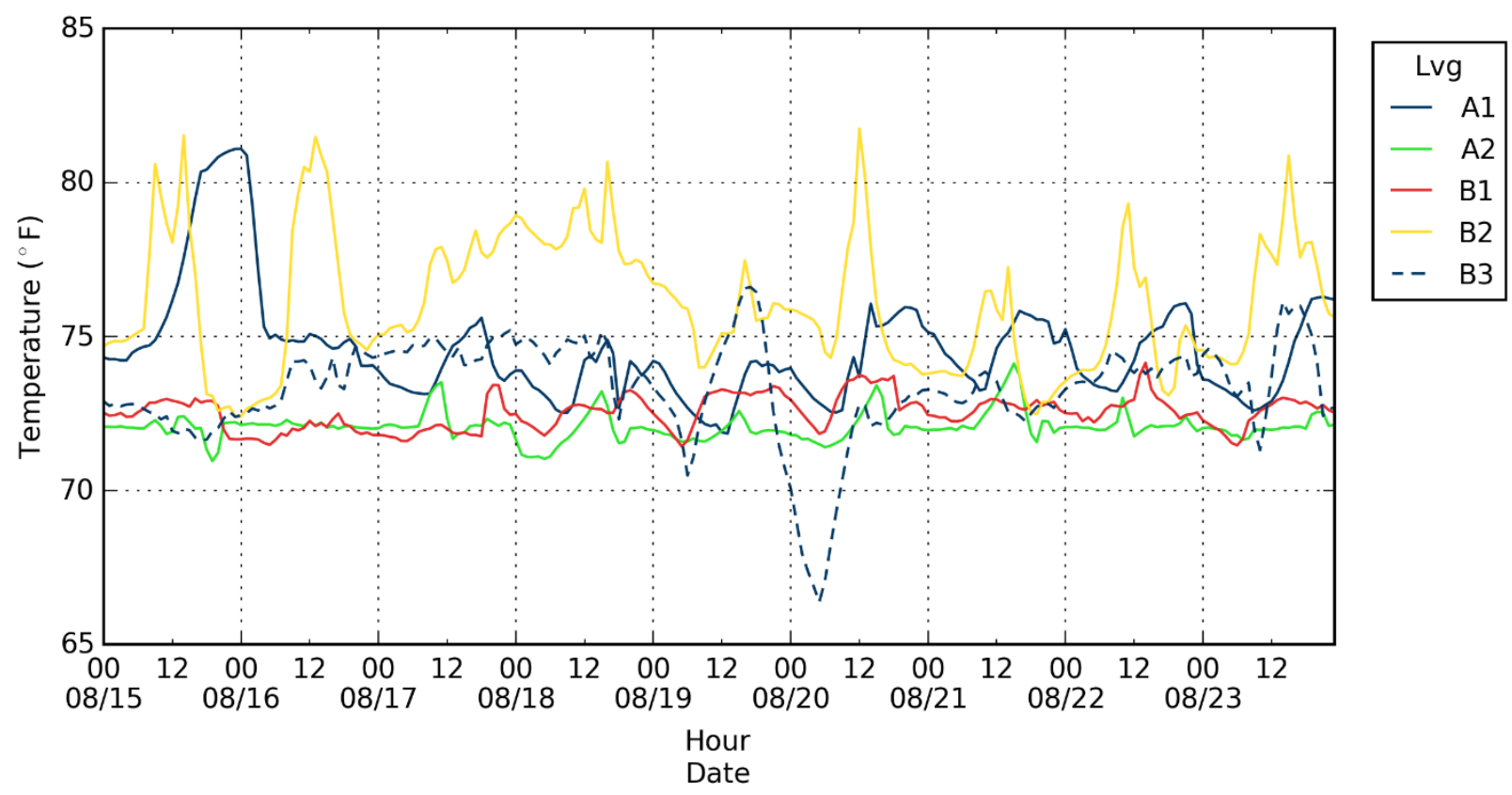

Figure 17. Hourly average thermostat temperature for each house

\subsection{Comfort Performance}

One of the primary comfort-related issues the builder wished to understand better was floor-tofloor stratification. In a three-story townhome, thermal buoyancy can have a significant impact on thermal uniformity. The team calculated the maximum room-to-room temperature difference for each minute in the analysis period. That is, the temperature from the coolest room was subtracted from the temperature of the warmest room. This always results in a $\Delta \mathrm{T} \geq 0^{\circ} \mathrm{F}$. Figure 18 presents the result of this calculation.

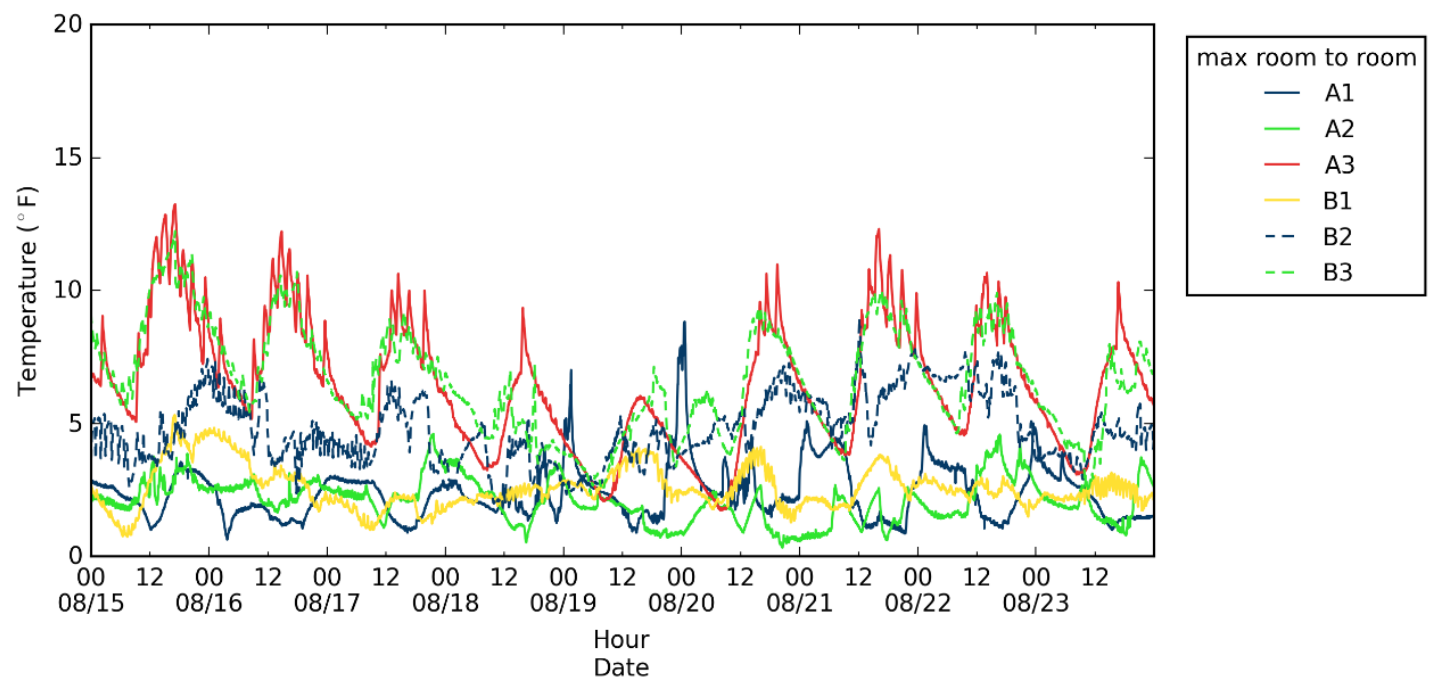

Figure 18. Room-to-room temperature difference by house 
The average room-to-room temperature differences for each house were as follows: Home A1 was $2.4^{\circ} \mathrm{F}$; Home A2 was $2.1^{\circ} \mathrm{F}$; Home A3 was $6.4^{\circ} \mathrm{F}$; Home B1 was $2.6^{\circ} \mathrm{F}$; Home B2 was $4.8^{\circ} \mathrm{F}$; and Home B3 was $6.6^{\circ} \mathrm{F}$. The two small-diameter systems showed better room-to-room uniformity for a number of possible reasons, as discussed below.

Figure 19 shows the relationship between the thermostat temperature and room temperatures. The thermostat for each central system was located in the middle floor. In addition to the measured data, a line representing the $3^{\circ} \mathrm{F}$ temperature band around the thermostat has been drawn. Any points outside this line are considered to fail the ACCA Manual RS comfort guidance (Rutkowski 1997). The foyer represents the first-floor temperature, and the master bedroom and bedroom 2 represent the top floor. The thermostat temperature is located on the middle floor. The rooms conditioned by the small-diameter system tended to be slightly cooler than the central living space. All top-floor rooms conditioned by the conventional systems tended to be slightly warmer than the thermostat, whereas the foyers were slightly cooler.

In Figure 19, $\mu$ represents the average difference between the rooms at the thermostat temperature. Also, Home A3 has been omitted because it contains a thermostat in each room shown; as such, it is not directly comparable to the central systems. 


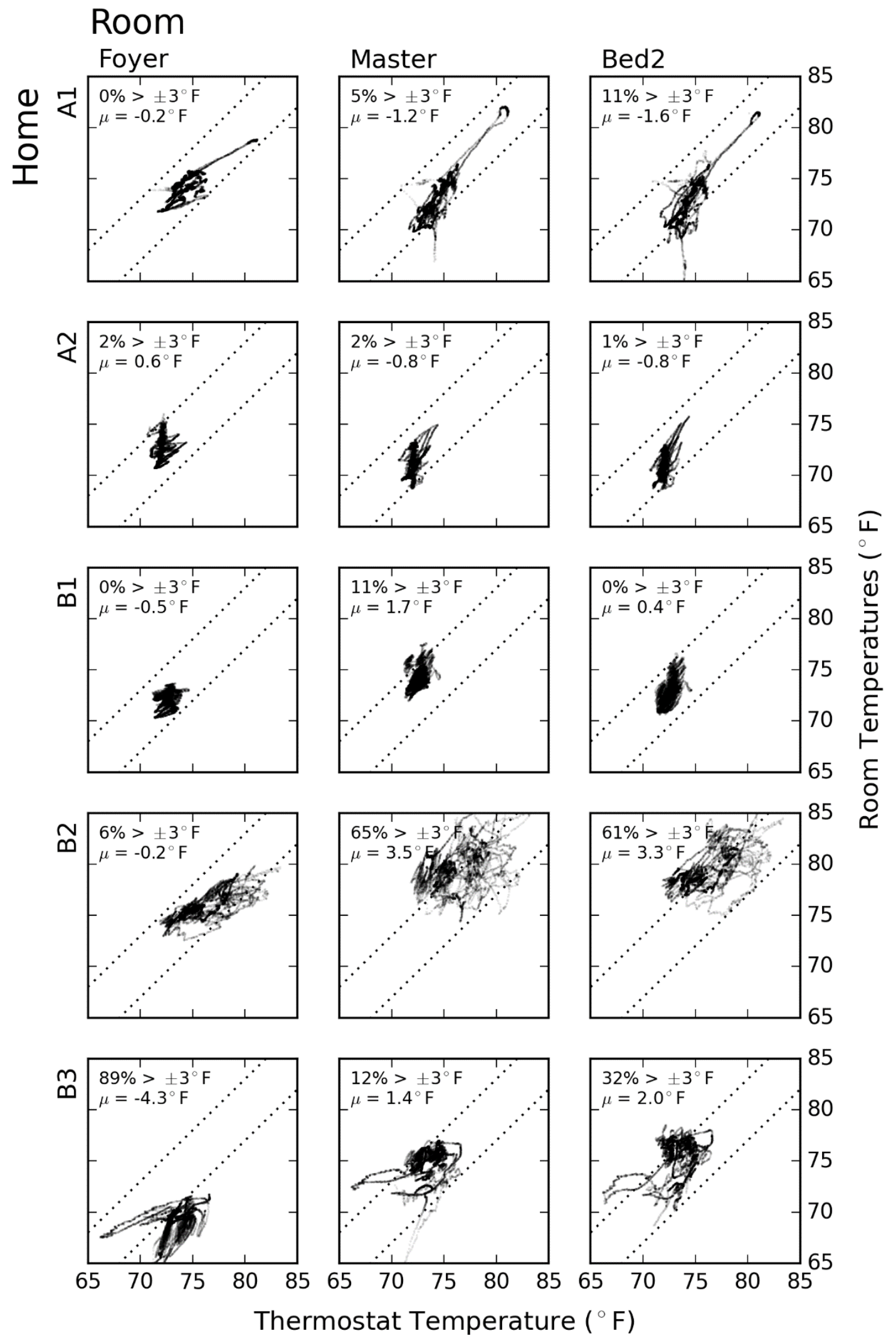

Figure 19. Room-to-thermostat temperature relationship 
Figure 19 contains data for periods when the system was both on and off. It may be of further interest to see if there is a difference in room-to-room uniformity with the system on rather than off. However, when evaluating the total system performance, the ability of the thermostat to understand and maintain uniform temperatures is critical, regardless of whether it has entered an "on" cycle. Further, given the relatively short cycle time observed for the systems, there is a challenge in deciding which data are impacted from the system being on and at which point any observed data are truly representative of the system-off state.

One interesting finding from Figure 19 is that the foyer in Home A2 was actually warmer than the rest of the house. This is contrary to the findings in the other homes and is against the expected result to thermal stratification. This may be a result of low airflow to the foyer level. If so, the foyer may not maintain a uniform temperature during the heating season.

The temperature excursion higher than $80^{\circ} \mathrm{F}$ observed in Home A1 is from a period when the entire system was switched off, because the home was unoccupied for a few days.

\subsubsection{System Operation Impact on Uniformity}

The following plots show the change in maximum room-to-room temperature variation for each home during system on and off cycles. Thin lines represent the instantaneous room-to-room temperature variation during each cycle; the starting and stopping points are shown with a small rectangular marker. Tracing a line from left to right through the origin shows a complete cycle from the moment the system shut off, through the home's drift period, through the last minute of the system's on cycle. When the system was on, if it was performing poorly, the rooms in the home would tend to drift apart, appearing as a line with positive slope. Figure 20 highlights some key features of these plots.

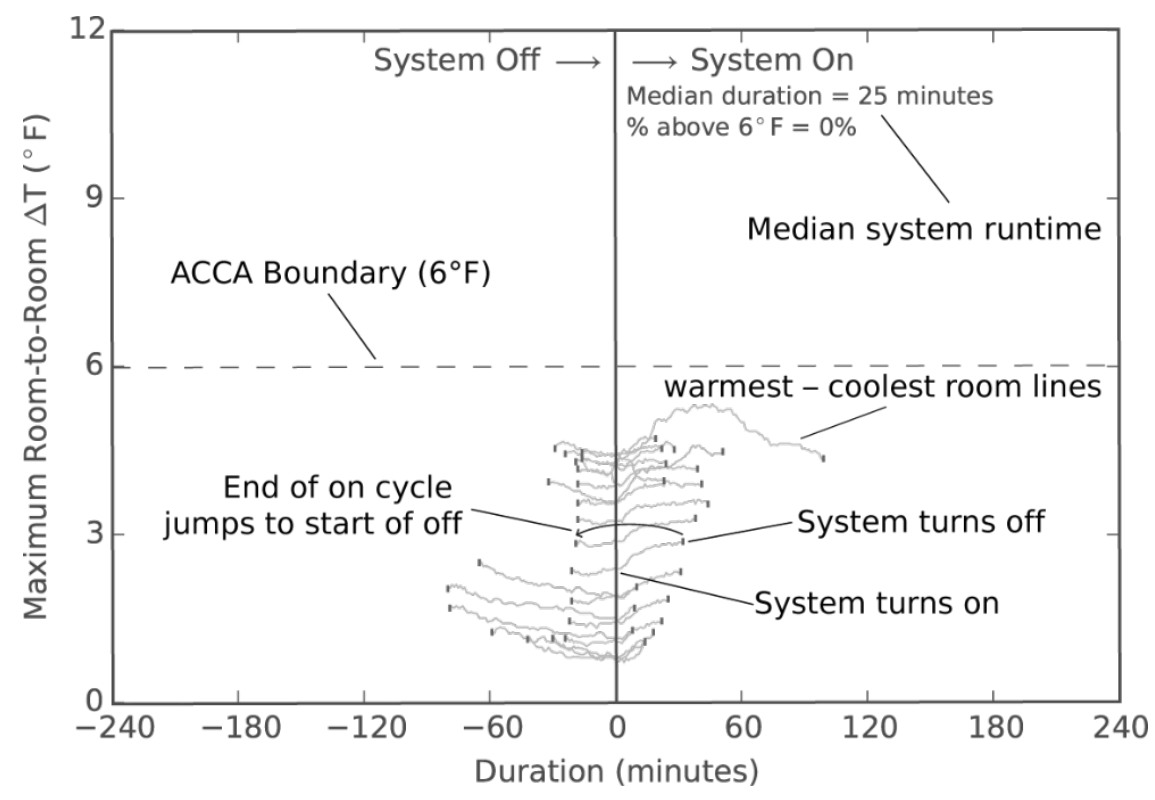

Figure 20. Example highlighting the features of a "hair" plot 
Results from the small-diameter system test homes are shown in Figure 21 and Figure 22. Both homes show data $100 \%$ within the ACCA Manual RS (Rutkowski 1997) suggested $6^{\circ} \mathrm{F}$ temperature band. During operation, the room temperature difference has little slope, suggesting a balanced and well-performing air distribution system. System median cycles are relatively short-10 min and $11 \mathrm{~min}$, respectively. This is an unexpected result, because the small-diameter system's heat pump is variable capacity. (However, its capacity varies only with outdoor temperature and not duration of cooling call or temperature at the thermostat versus the set point.) Because the system off cycles also are rather short, this indicates a short-cycling problem caused by an oversized heat pump.

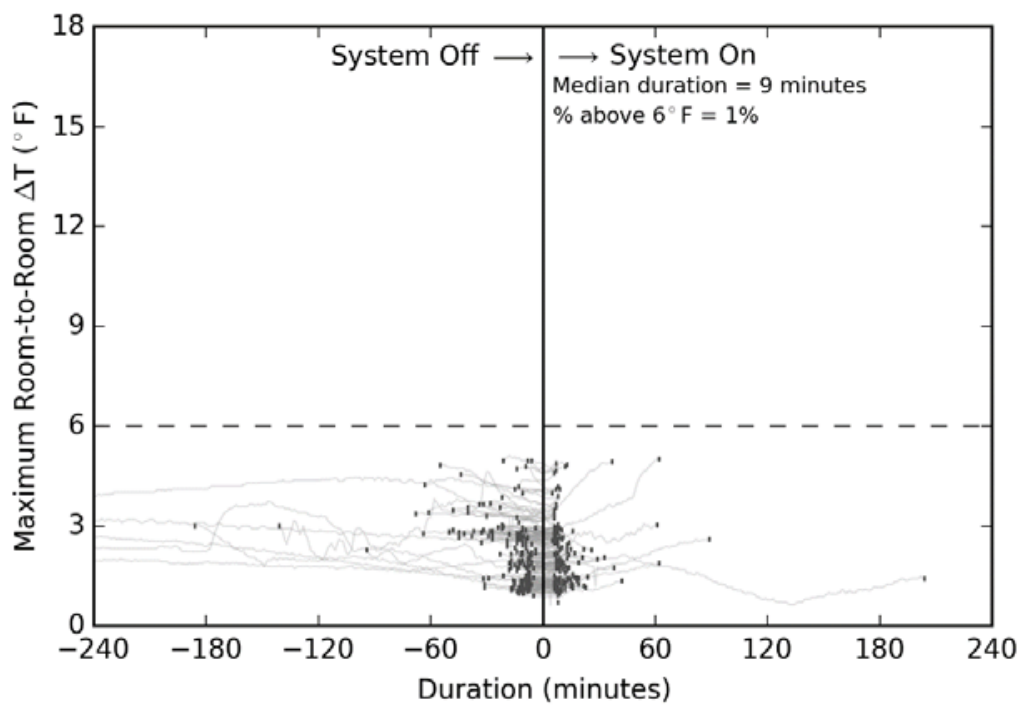

Figure 21. Home A1: Room-to-room temperature change during operation

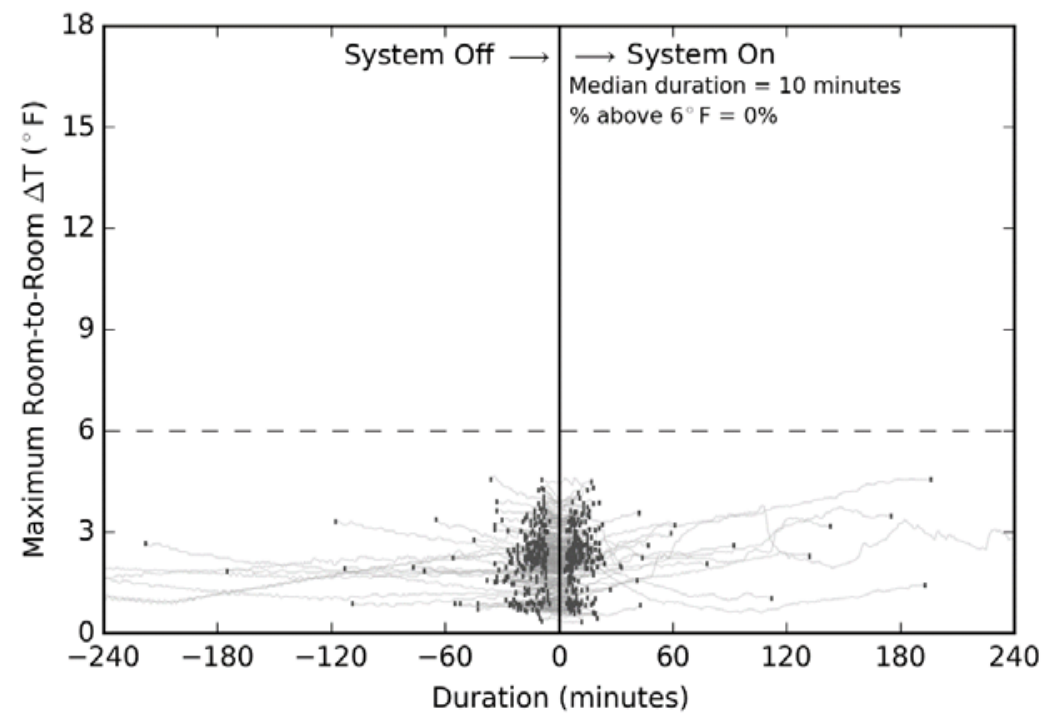

Figure 22. Home A2: Room-to-room temperature change during operation 
Room-to-room temperature performance of the builder's standard air-conditioning equipment is shown in Figure 23 through Figure 25.

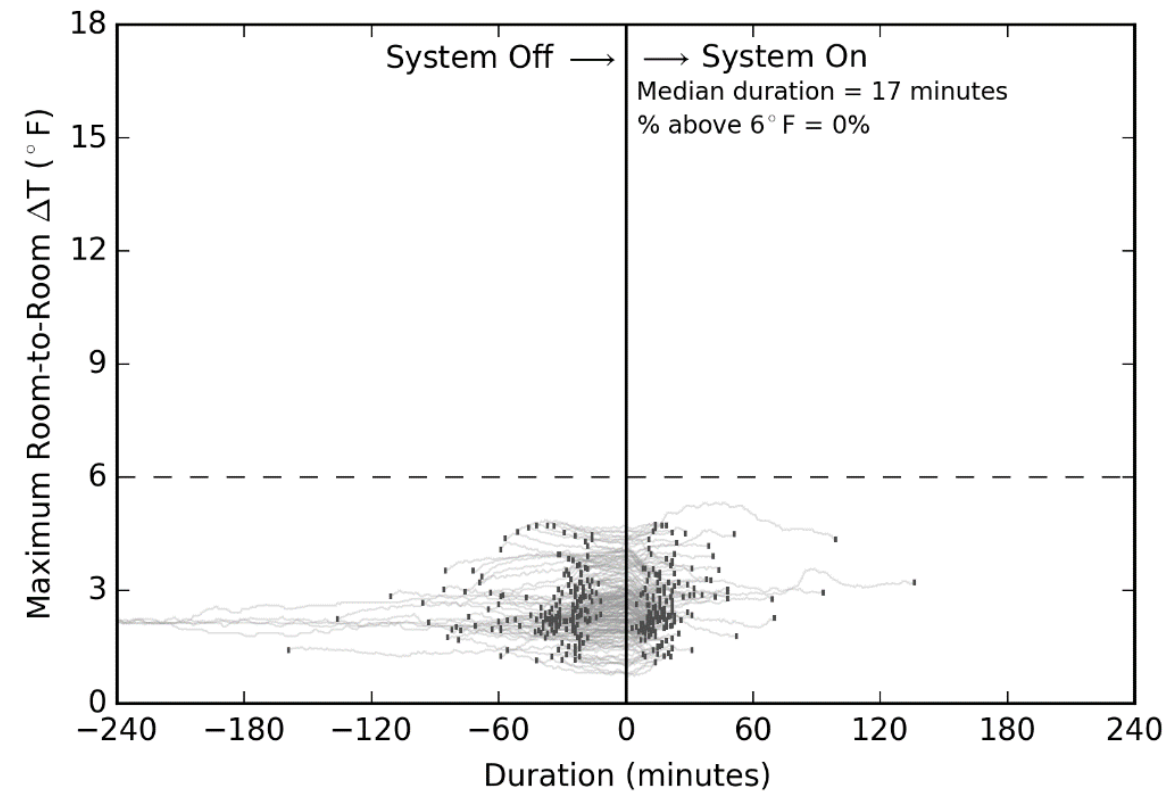

Figure 23. Home B1: Room-to-room temperature change during operation

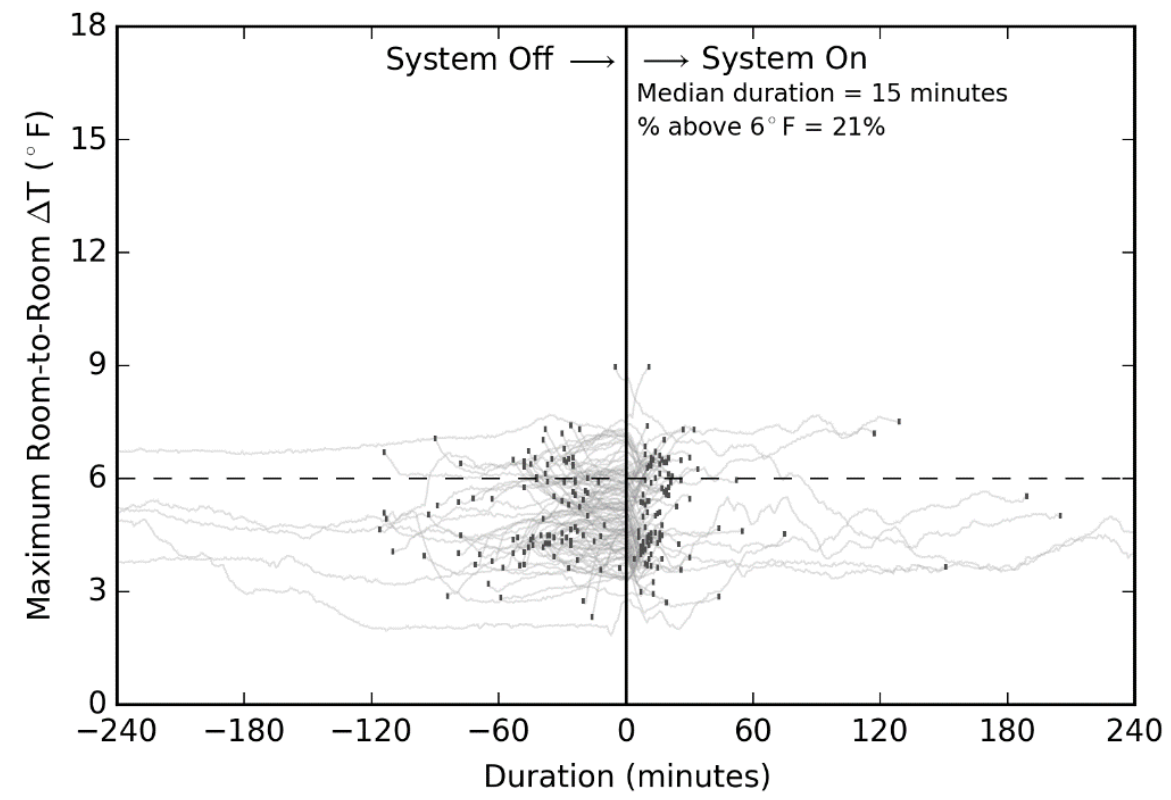

Figure 24. Home B2: Room-to-room temperature change during operation 


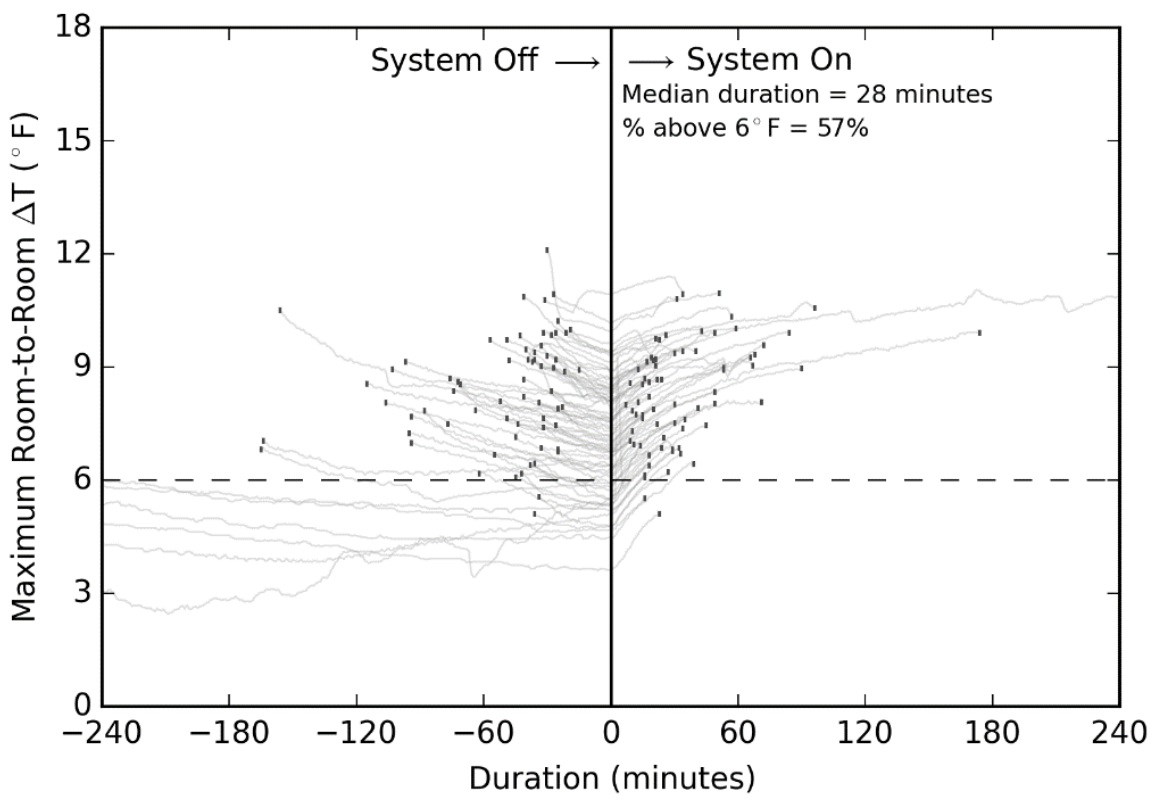

Figure 25. Home B3: Room-to-room temperature change during operation

The builder's standard HVAC equipment showed a tendency toward diverging temperatures in two of the standard townhomes. Room-to-room temperatures in one of the standard townhomes (Home B1) remained relatively constant. The diverging room-to-room temperatures suggest the system may not be well balanced. ${ }^{4}$ The first-floor foyers in Home B2 and Home B3 were consistently the coldest rooms in these two townhomes. Home B1 showed better performance, and its foyer temperature was closer to its mean temperature.

The room-to-room temperatures in Home $\mathrm{B} 2$ consistently exceeded the $6^{\circ} \mathrm{F}$ temperature range. In addition to the potential for poor supply register balancing, the family had a newborn child and may have thus had increased internal gains or used a humidifier. Low measured duct leakage (5 CFM @ 25 Pa) suggests that duct leakage did not significantly impact the air distribution performance.

Average hourly room-to-room temperature differences have been plotted against the outdoor temperature, as shown in Figure 26. Based on these data, a linear regression line has been calculated and shown on the plot, along with the $\mathrm{R}^{2}$ value. The data included in this plot are from July 21 through August 17, 2015.

\footnotetext{
${ }^{4}$ This project used real-world test homes in which the HVAC contractor performed its standard installation. Future work could look at the variability in balancing between systems installed by the same contractor to understand if there is a craftsmanship gap. An additional point of study could be to understand the probability of getting a wellbalanced installation for the small-diameter ductwork versus traditional-sized ductwork.
} 


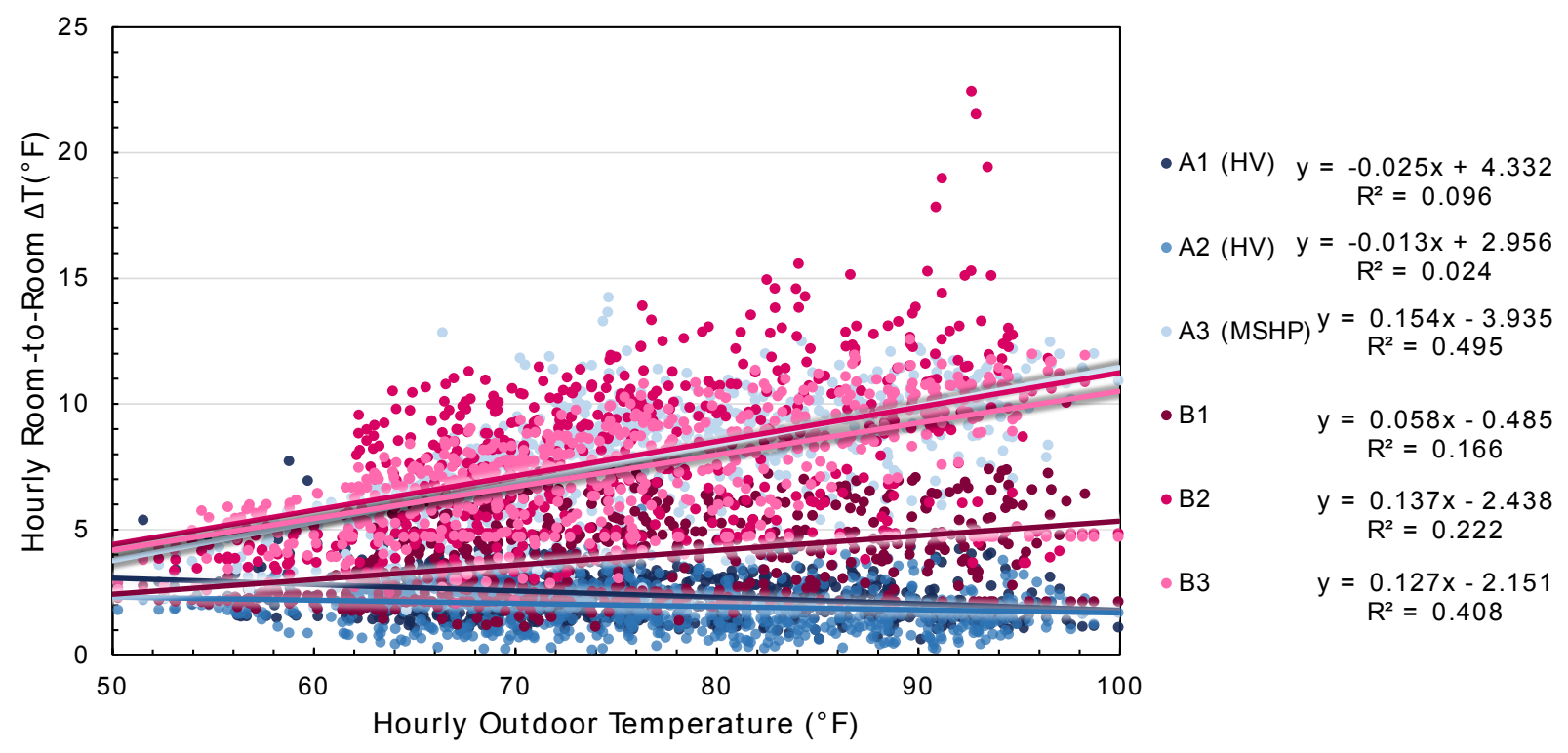

Figure 26. Hourly average room-to-room temperature versus outdoor temperature

The results of this analysis show a poor correlation for each linear regression; however, the significant finding is the relative room-to-room temperature difference between each home. One cause of the low $\mathrm{R}^{2}$ values ( 0.06 to 0.51 ) is the noise from using hourly data. There is some lag between outdoor conditions and their impact on the interior of the townhome. Furthermore, the two small-diameter systems show very little impact from outdoor conditions and, as such, have a slope close to zero. The residual values from the linear regression will thus appear almost identical to the input data.

The data show an apparent difference between the two small-diameter systems and the builder's standard system. The small-diameter system again shows lower room-to-room temperature differences and, in fact, shows improved performance with hotter outdoor temperatures. One potential reason for the improvement is that when the system ran more often on hotter days, it did a better job of mixing air within the entire house relative to the standard system. Meanwhile, stratification with the standard system became worse as the outdoor temperature increased.

\subsubsection{ASHRAE Standard 55 and Psychrometrics}

The ability of a system to maintain a uniform temperature over time is an important performance characteristic. If system cycles cause rapid ramps or drifts in room temperature, an occupant may find this uncomfortable.

The "hair plot" showing repeated system evolution over time has been modified in this section. Rather than a single line for the entire house, each room is represented as its own line, which significantly increases the total number of lines.

The temperature in each zone was sliced by system on and off periods and normalized such that the start of each on cycle is $0^{\circ} \mathrm{F}$. The ASHRAE Standard 55 drift and ramp failure boundary (ASHRAE 2013) then was shown as a gray area, and any occurrences where the room 
temperature deviated beyond this boundary were counted. Figure 27 through Figure 31 present the results of this analysis. The two small-diameter systems (Figure 27 and Figure 28) show negligible ramp failures. The builder's standard system shows some failure in the center unit, Home B2 (Figure 30). This may be due to the consistently sized outdoor unit (2 tons), regardless of actual load. The center unit has a smaller surface area and lower load, which resulted in more rapid temperature ramps when the system cycled on. This townhome's southern bedroom also showed a tendency to overheat during the afternoon, which appeared as a ramp failure.

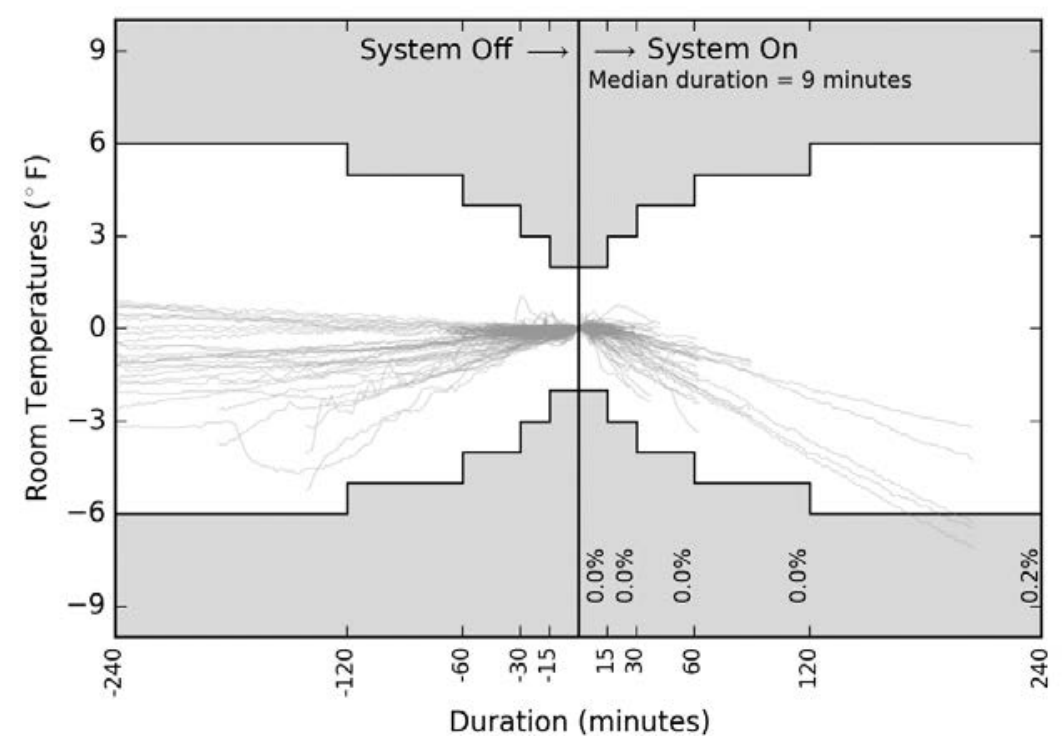

Figure 27. Home A1: Small diameter-room temperature versus system runtime

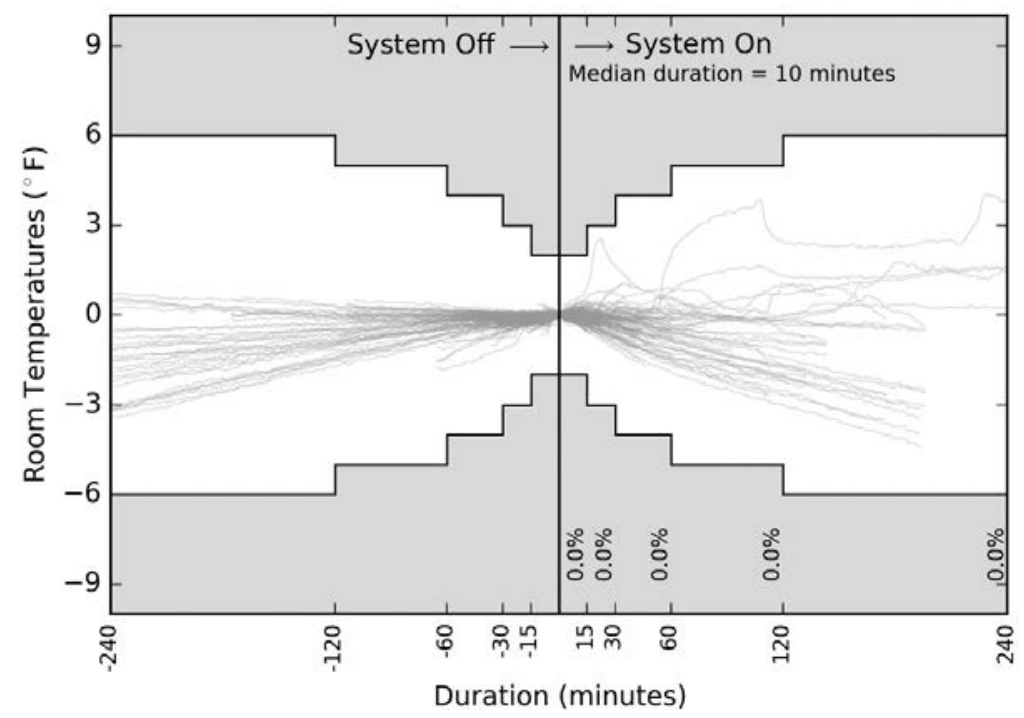

Figure 28. Home A2: Small diameter-room temperature versus system runtime 


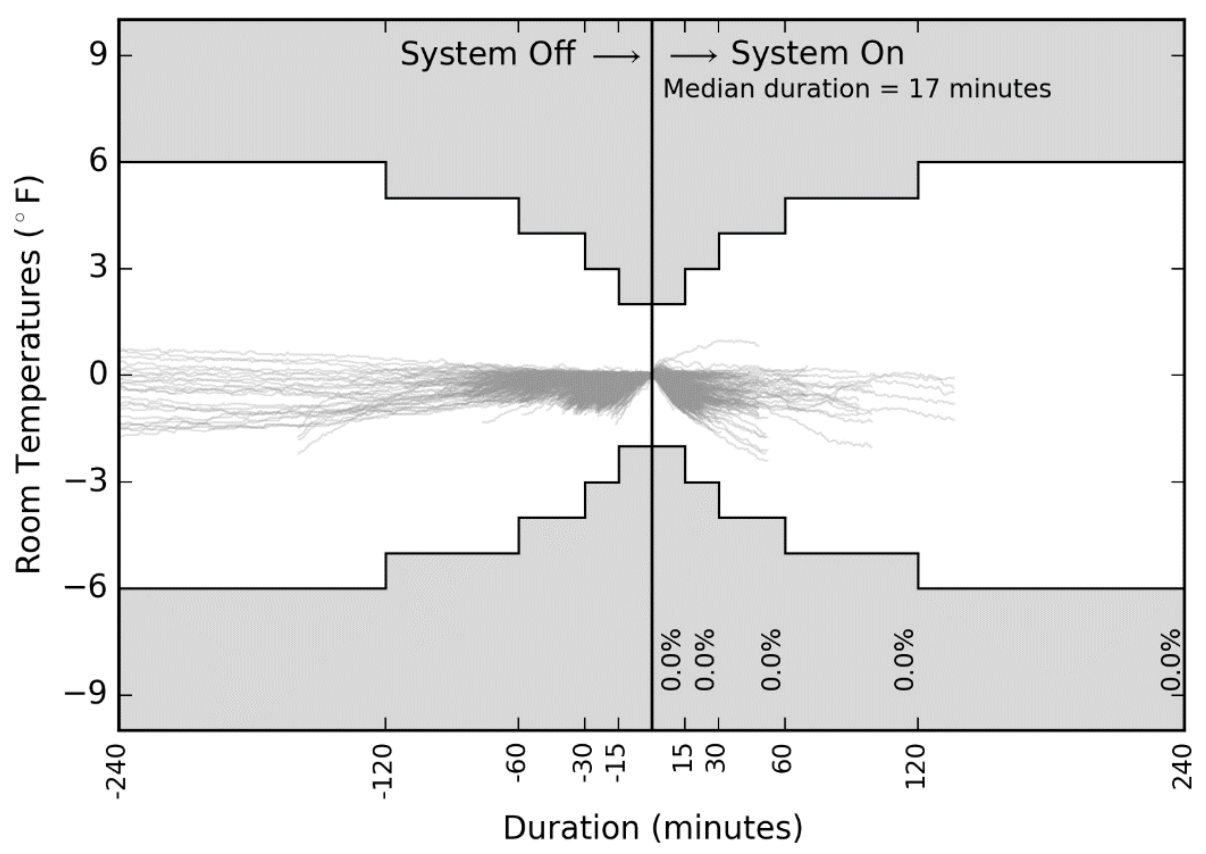

Figure 29. Home B1: Standard-room temperature versus system runtime

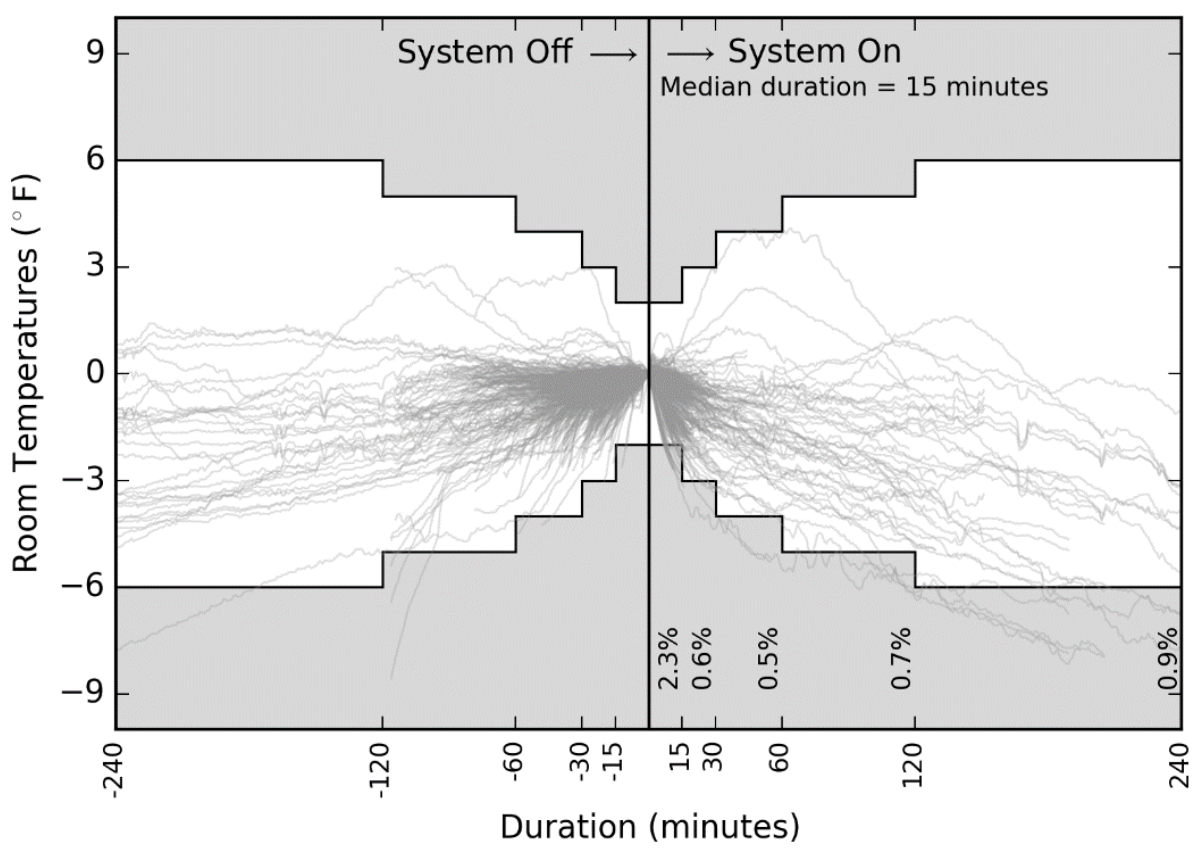

Figure 30. Home B2: Standard-room temperature versus system runtime 


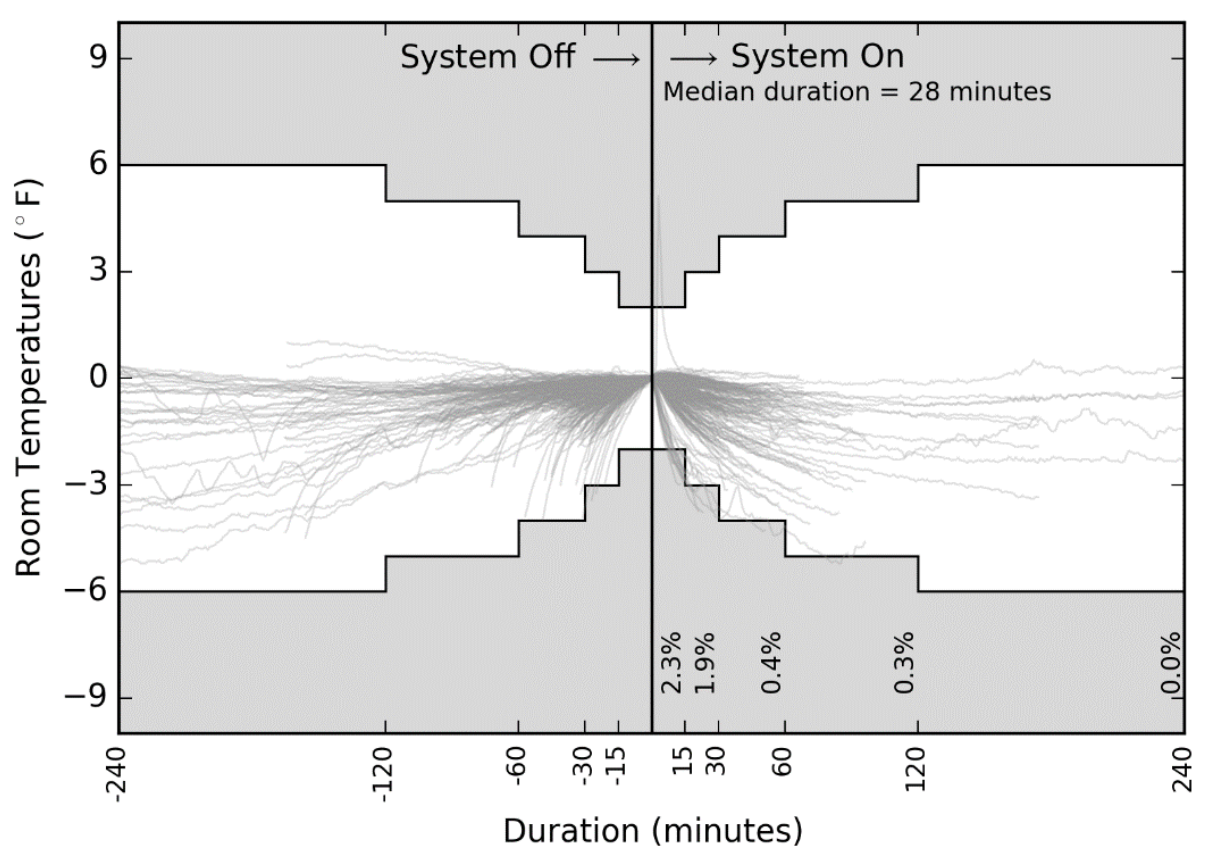

Figure 31. Home B3: Standard-room temperature versus system runtime

The conclusion from this analysis is that neither system showed a significant percentage (i.e., greater than $5 \%$ ) of time when an occupant in a particular room might notice a rapid temperature change. The small-diameter system provided a more uniform temperature in each room over time, despite a shorter cycle time. The small-diameter system was sized smaller and closer to the load in each home (1.5 tons versus 2 tons). This may have been another reason for the slower temperature changes.

In Figure 30, Home B2 appears to show much more erratic room temperature fluctuations; however, there is only a small percentage of time when an occupant might notice the change and find it uncomfortable according to the temperature uniformity standard.

To understand how each house performed relative to the ASHRAE Standard 55 comfort box (ASHRAE 2013), data from each room in each house were plotted on a psychrometric chart, as shown in Figure 32 through Figure 37. Measurements that fell within the ASHRAE Standard 55 comfort box were counted. Data from the same period (August 15, 2015, through August 23, 2015 ) as the previous analysis are presented. The comfort box assumes occupants have a 0.5 clothing level and a 1 metabolic rate.

The majority of measured data fall outside the suggested ASHRAE Standard 55 comfort box. Further discussion following the figures elaborates on this finding.

Home B2 shows periods of relative humidity that exceed $100 \%$. The accuracy of the CS210 sensor significantly drops off near $100 \%$ relative humidity. The deviation can be explained by the sensor uncertainty alone. 


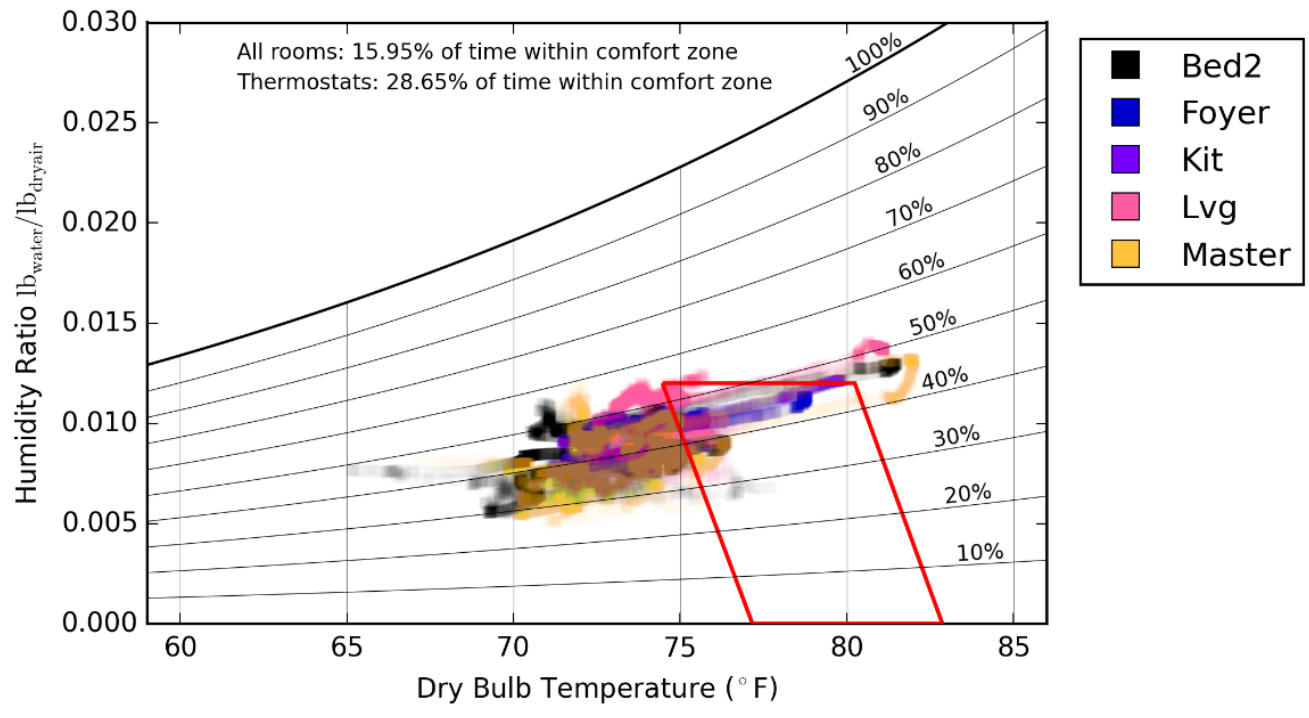

Figure 32. Home A1: Small-diameter-psychrometric chart

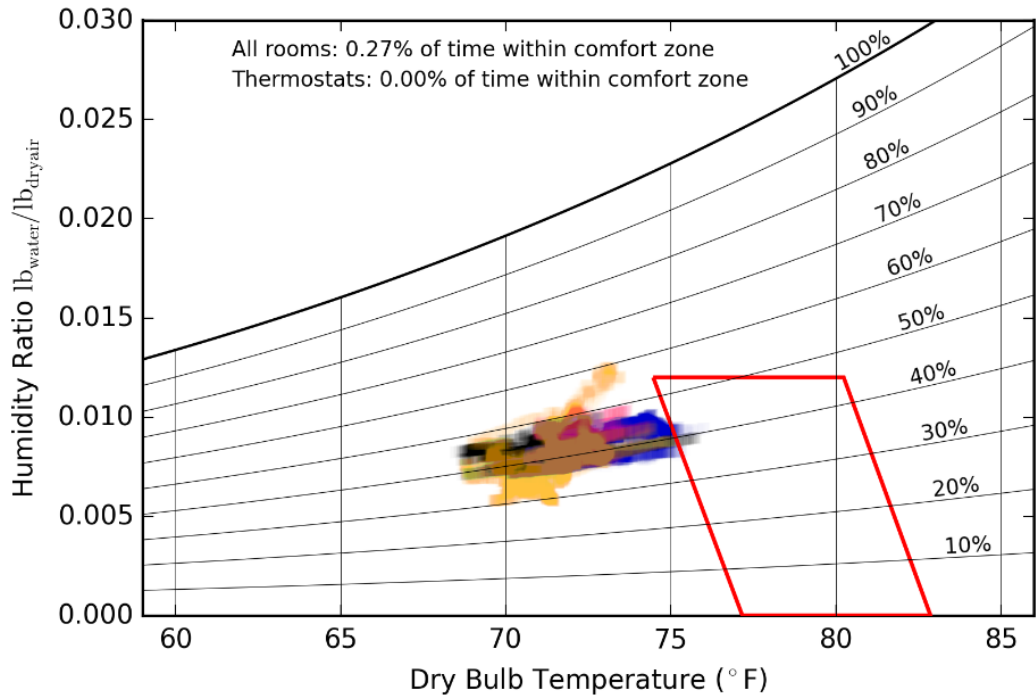

\begin{tabular}{|ll|}
\hline$\square$ & Bed2 \\
$\square$ & Foyer \\
$\square$ & Lvg \\
$\square$ & Master \\
\hline
\end{tabular}

Figure 33. Home A2: Small diameter-psychrometric chart 


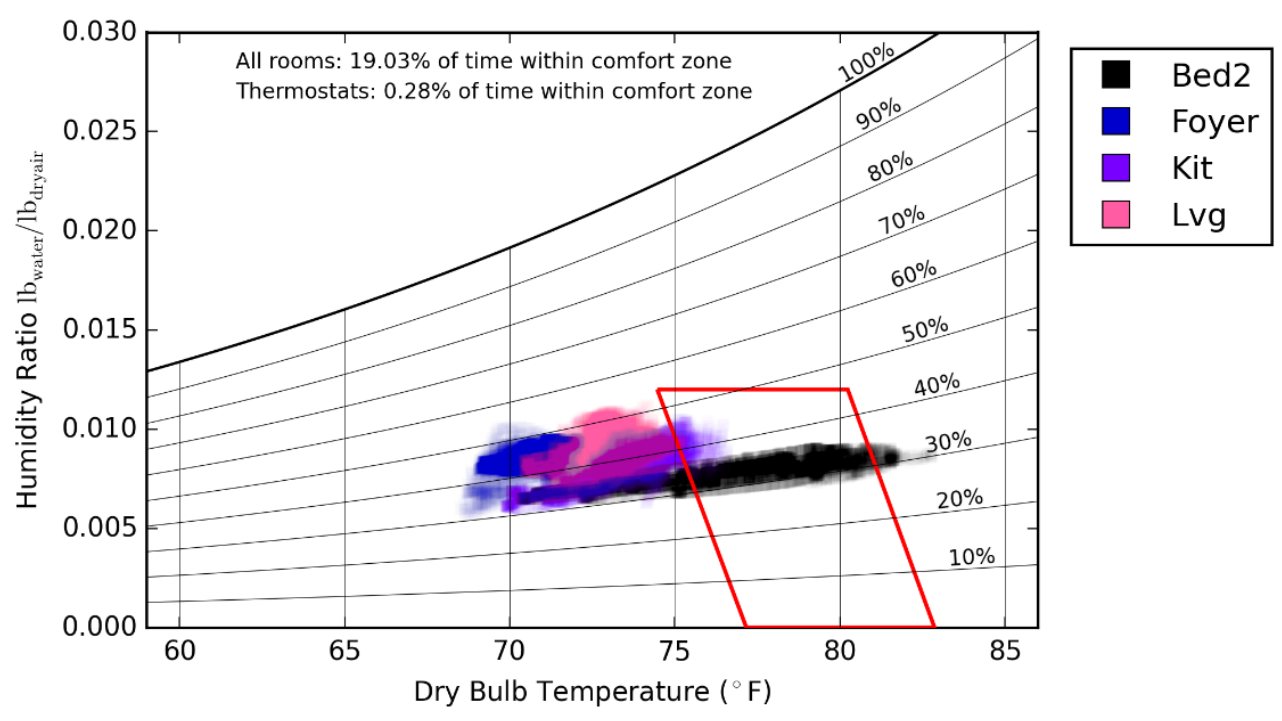

Figure 34. Home A3: Mini-split heat pump—psychrometric chart

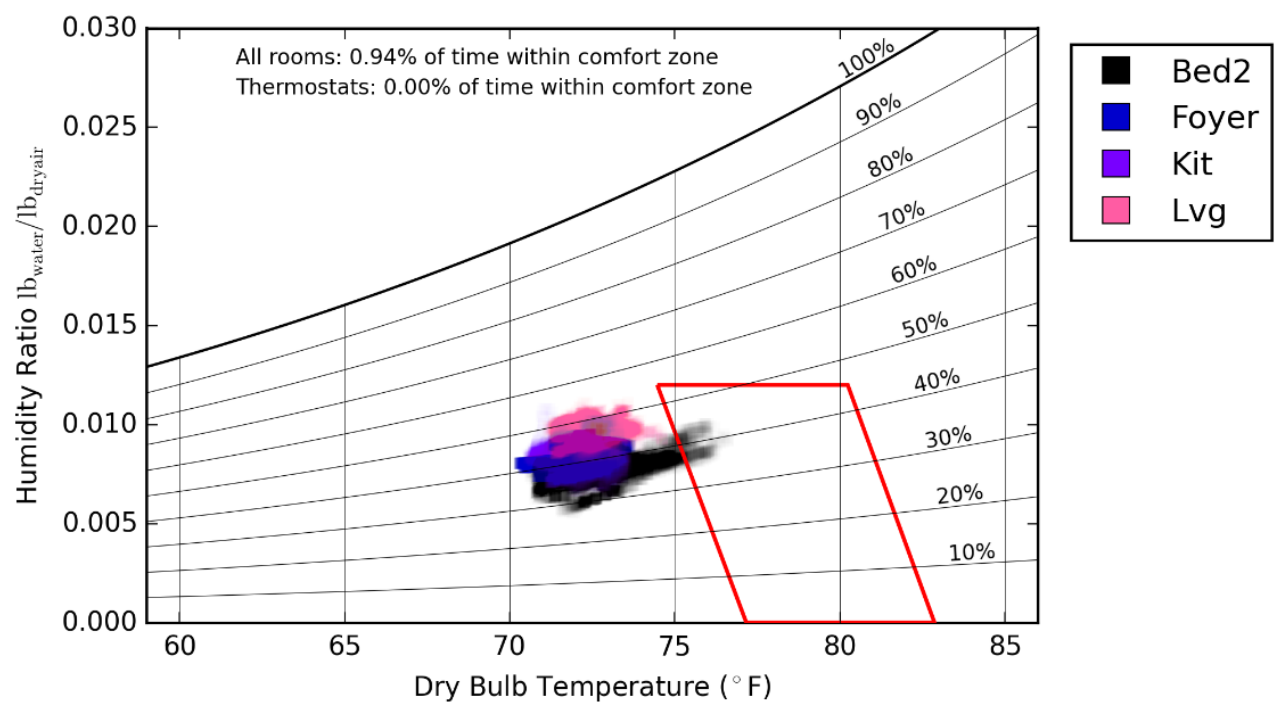

Figure 35. Home B1: Standard-psychrometric chart 


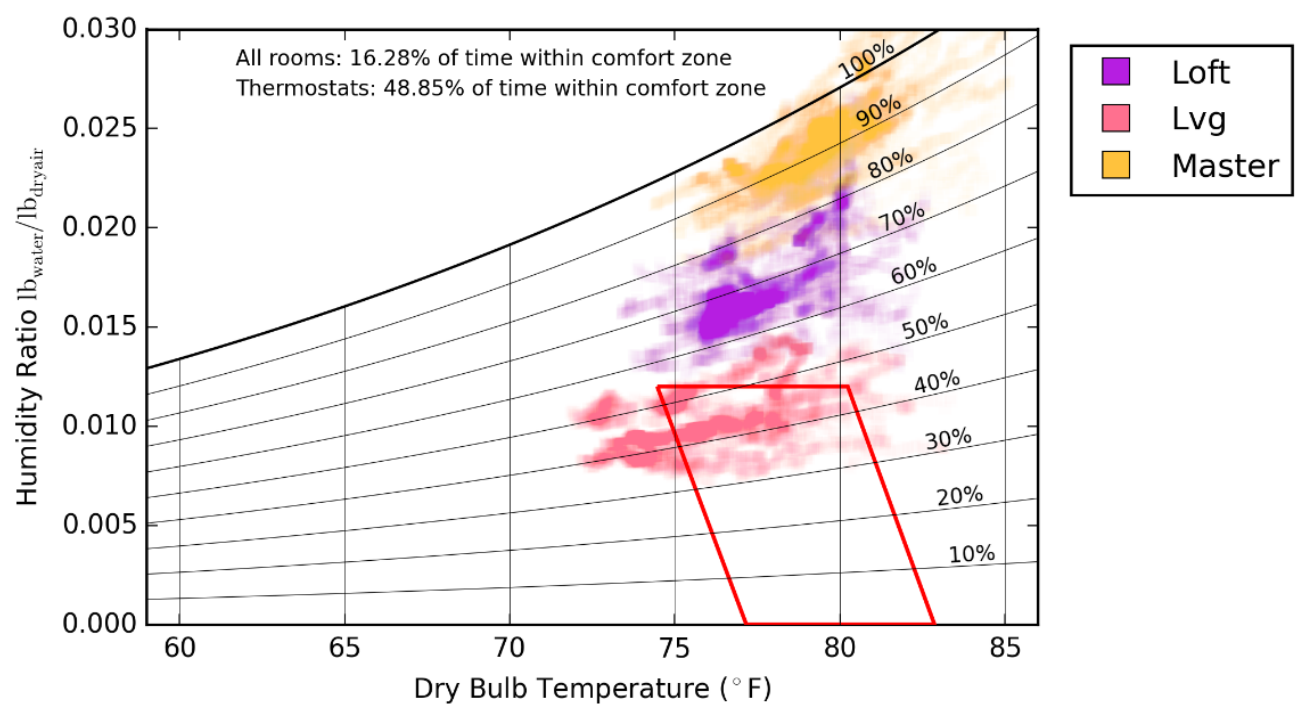

Figure 36. Home B2: Standard-psychrometric chart

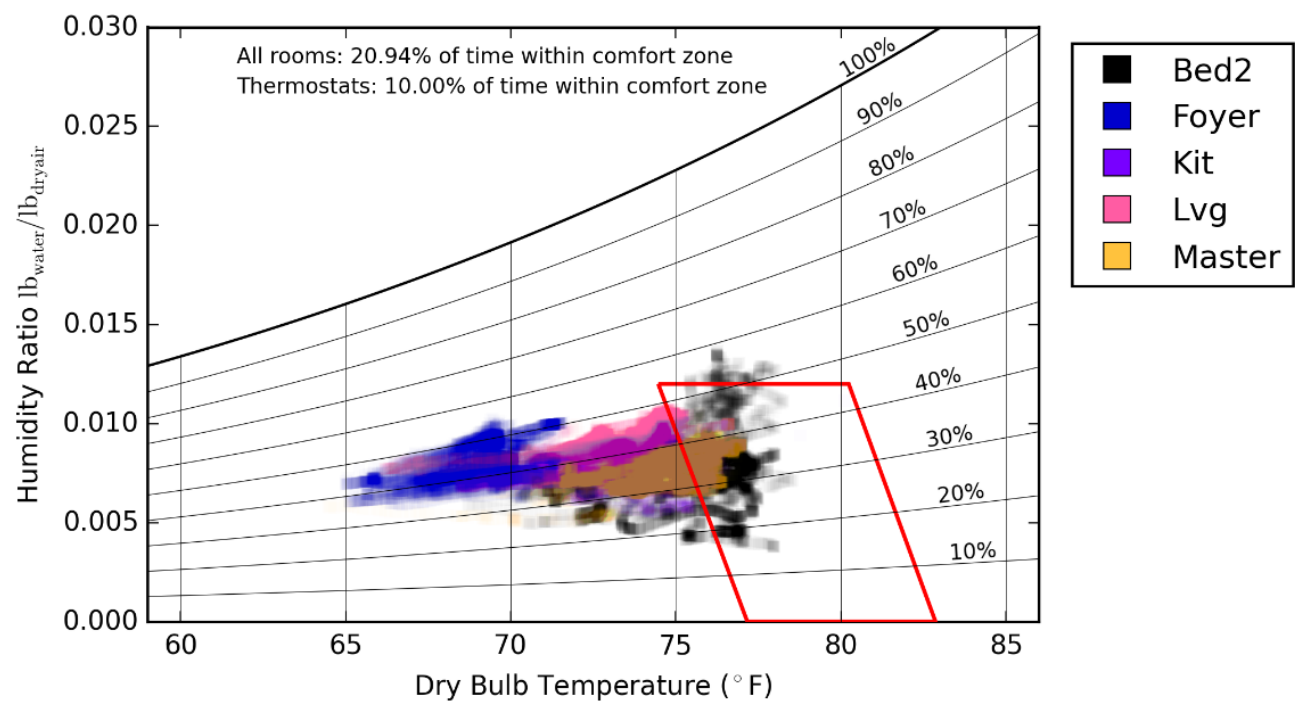

Figure 37. Home B3: Standard-psychrometric chart

As shown in Figure 32 through Figure 37, the measured data fall within the ASHRAE Standard 55 comfort box only a small percentage of time. This box is representative of conditions in which $80 \%$ of individuals will be comfortable. Typically, however, the actual indoor temperature is below the predicted comfortable temperature value. Both the thermostat and zone air temperatures followed this trend, and there were no known comfort complaints, suggesting this was the occupant's preference. Factors influencing the actual set point temperature may be increased occupant clothing levels; however, this is unlikely in the summer months as the 0.5 clothing value already assumes pants and a long-sleeve shirt. Results from Poerschke and Beach (2016) also show an occupant preference for cooler indoor temperatures. The significant conclusion from these data is that the ASHRAE Standard 55 comfort box may not be a strong indicator of comfort in residential situations. 


\subsection{Energy Performance}

Cooling energy and whole-house energy consumption data are presented in this section. The same data range was used for these data as for the comfort performance: August 15, 2015, through August 23, 2015. Figure 38 presents a cumulative summation of the cooling energy. This graph shows the mini-split heat pump townhouse (Home A3) used the most energy of all the townhomes. The other townhomes used a similar amount of energy. Home A1 starts with low energy consumption, likely because of a few days of unoccupancy, as seen in the carbon dioxide chart. If the period of unoccupancy were to be removed from the cumulative summation for all the homes, Home A1 would show the highest energy use of all units (except the ductless Home A3). For only the period of August 20, 2015, through August 24, 2015, Home A1 used 10\% more energy than Home B1.

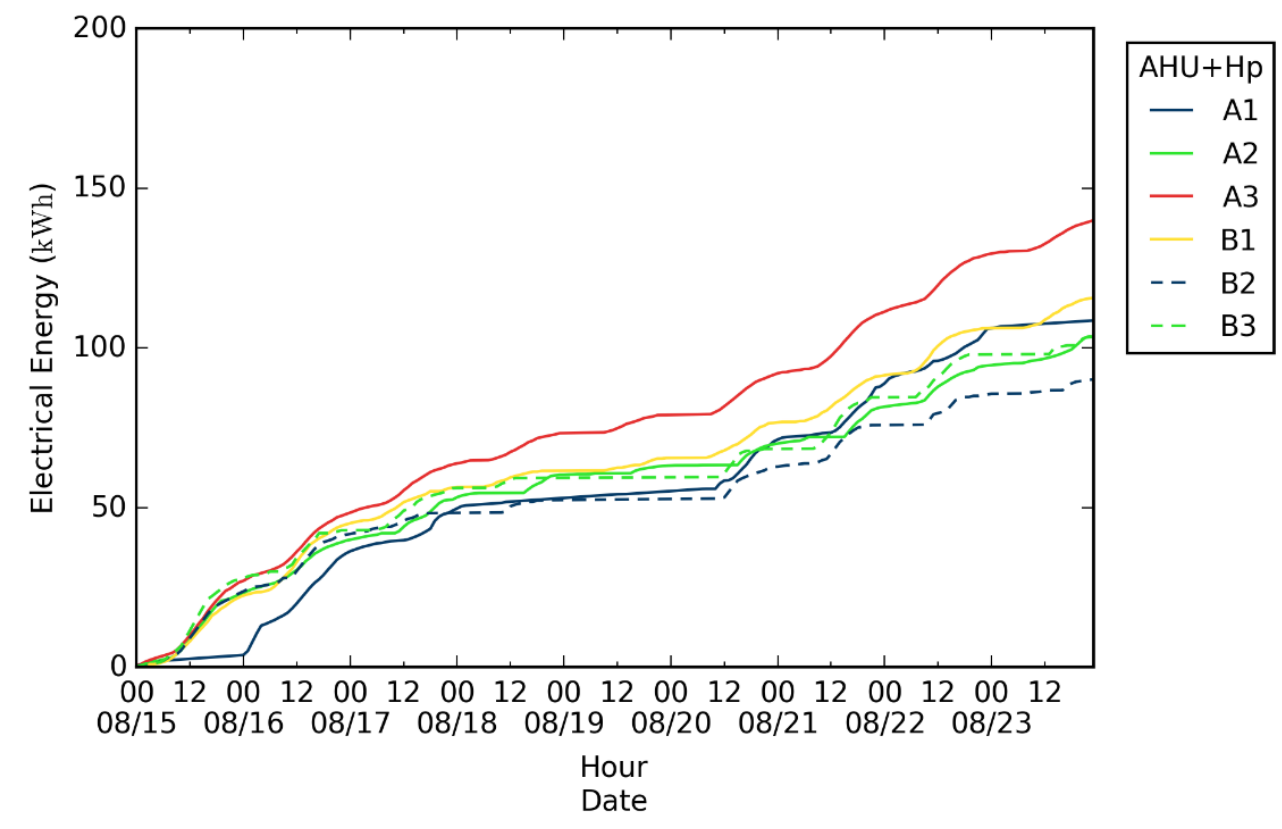

Figure 38. Cumulative energy consumed by the cooling equipment in each townhome

Cumulative whole-house energy consumption is plotted in Figure 39. Despite using the lowest energy for cooling, Home B2 used the most whole-house energy overall. This may be due to a higher baseload electrical energy consumption associated with a newborn in the house. 


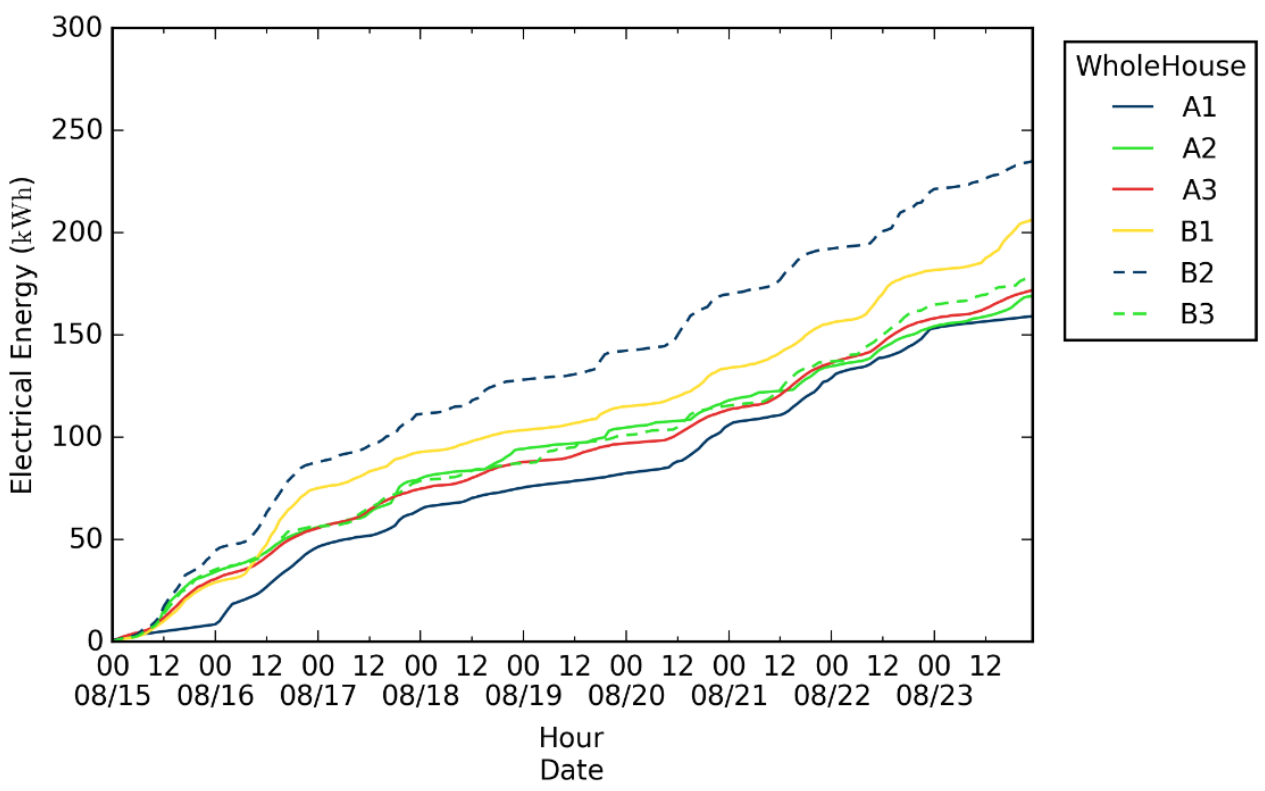

Figure 39. Cumulative whole-house electrical energy consumed by each townhome

Table 6 presents a summary of the performance of each system. As with any occupied test house scenario, these results are highly dependent on a number of factors (e.g., set points, window schedule, airflow balancing) and must be understood as such. These are real-world results, which may have uncertainties underlying the observed differences.

Of the three systems tested, the mini-split heat pump system consumed the most energy during the test period. This was in spite of the townhome being unoccupied and thus having the lowest internal gains, as well as the highest-capacity outdoor unit ( 3 tons). Furthermore, the set points for the two head units on the top floor were adjusted to $73.4^{\circ} \mathrm{F}$ and $78.8^{\circ} \mathrm{F}$, which are higher than the set points used in the other townhomes. One potential cause of this may be that the occupants were able to take advantage of free cooling during the nights by opening windows. Also, the unoccupied townhome unit had no window treatments. The townhome had minimal useful exterior shading or overhangs. Additional solar heat gains contributed to the increased energy consumption.

Table 6. Summary of Home Performance

\begin{tabular}{c|c|c|c|c|c|c}
\hline & A1 & A2 & A3 & B1 & B2 & B3 \\
\hline Total HVAC Energy $(\mathbf{k W h})$ & 109 & 103 & 140 & 116 & 90 & 104 \\
\hline Average Daily Runtime $(\mathbf{m i n})$ & 297 & 562 & $\mathrm{~N} / \mathrm{A}^{\mathrm{a}}$ & 415 & 358 & 324 \\
Average Thermostat $\left({ }^{\circ} \mathbf{F}\right)$ & 74.6 & 72.1 & 72.8 & 72.5 & 76.1 & 73.3 \\
\hline Average Room-to-Room $\mathbf{\Delta} \mathbf{T}\left({ }^{\circ} \mathbf{F}\right)$ & 2.4 & 2.1 & 6.4 & 2.6 & 4.8 & 6.6 \\
\hline
\end{tabular}

${ }^{a}$ The MSHP house runtime was room dependent and not directly comparable to the central systems.

\subsection{Air Leakage Testing}

Results from the blower door air leakage testing are presented in this section. Guarded blower door testing was performed only on the small-diameter test houses. Each house was tested individually, and then each end unit was tested with the center unit depressurized. Finally, all 
three units in the triplex were depressurized simultaneously. Table 7 presents the test results. Highlighted cells have been depressurized in each test case, and the effective leakage area (ELA) and calculated air changes per hour value are presented.

Table 7. Measurements and Equipment

\begin{tabular}{|c|c|c|c|c|c|c|}
\hline & \multicolumn{2}{|c|}{ A1 } & \multicolumn{2}{|c|}{ A2 } & \multicolumn{2}{|c|}{ A3 } \\
\hline & -50 & $\mathrm{~Pa}$ & & & & \\
\hline ELA & 47.1 & $\mathrm{ft}^{2}$ & & & & \\
\hline Air Changes & 2.97 & $\mathrm{ACH}$ & & & & \\
\hline & & & -50 & $\mathrm{~Pa}$ & & \\
\hline ELA & & & 41.2 & $\mathrm{ft}^{2}$ & & \\
\hline Air Changes & & & 3.49 & $\mathrm{ACH}$ & & \\
\hline & & & & & -50 & $\mathrm{~Pa}$ \\
\hline ELA & & & & & 54.6 & $\mathrm{ft}^{2}$ \\
\hline Air Changes & & & & & 3.98 & $\mathrm{ACH}$ \\
\hline & A1 & & A2 & & $\mathbf{A 3}$ & \\
\hline & -50 & $\mathrm{~Pa}$ & -50 & $\mathrm{~Pa}$ & & \\
\hline ELA & 41.9 & $\mathrm{ft}^{2}$ & 42 & $\mathrm{ft}^{2}$ & & \\
\hline Air Changes & 2.64 & $\mathrm{ACH}$ & 3.56 & $\mathrm{ACH}$ & & \\
\hline & & & -50 & $\mathrm{~Pa}$ & -50 & $\mathrm{~Pa}$ \\
\hline ELA & & & 3.05 & $\mathrm{ft}^{2}$ & 3.86 & $\mathrm{ft}^{2}$ \\
\hline Air Changes & & & 36 & $\mathrm{ACH}$ & 53 & $\mathrm{ACH}$ \\
\hline & -50 & $\mathrm{~Pa}$ & -50 & $\mathrm{~Pa}$ & -50 & $\mathrm{~Pa}$ \\
\hline ELA & & $\mathrm{ft}^{2}$ & 37.9 & $\mathrm{ft}^{2}$ & & $\mathrm{ft}^{2}$ \\
\hline Air Changes & & $\mathrm{ACH}$ & 3.21 & $\mathrm{ACH}$ & & $\mathrm{ACH}$ \\
\hline
\end{tabular}

$\mathrm{ACH}$ is air changes at 50 Pascals pressure difference indoor - outdoor.

The guarded tests do not show clear leakage between units. In the case of Home A1 and Home A2 being depressurized, the ELA actually increases for Home A2. The published sensor accuracy is $3 \%$, and all measured differences were within the published uncertainty. 


\section{Conclusions}

Each research question is answered in this section, and additional lessons learned are discussed.

\subsection{Research Questions Answered}

What are the differences in performance of a small-diameter duct system compared to a conventionally sized duct system as judged by energy consumption and comfort? Specifically, the following metrics will be used:

- ACCA Manual RS (Rutkowski 1997)

- ASHRAE Standard 55 (ASHRAE 2013)

- System runtime

- Energy consumption by each unit.

Measured data indicate the small-diameter system provided more uniform temperatures floor to floor throughout the home. During a test period of 9 days in August 2015, the average room-toroom temperature difference of the small-diameter townhomes was $2.4^{\circ} \mathrm{F}$ (Home A1) and $2.1^{\circ} \mathrm{F}$ (Home A2), whereas the average room-to-room temperature difference of the builder's standard townhome was $2.6^{\circ} \mathrm{F}$ (Home B1), $4.8^{\circ} \mathrm{F}$ (Home B2), and $6.6^{\circ} \mathrm{F}$ (Home B3). The percentage of time the small-diameter system failed the ACCA Manual RS room-to-room guidance (Rutkowski 1997) was 1\% (Home A1) and 0\% (Home A2), whereas the standard system had a significantly higher failure rate in some instances: 0\% (Home B1), 21\% (Home B2), and 57\% (Home B3).

An analysis of the room-to-thermostat temperature difference showed two distinct behaviors between the systems. The small-diameter system kept all rooms within $3^{\circ} \mathrm{F}$. The conventional system showed a tendency for the top-floor rooms to be warmer than the middle floor and the bottom floor to be cooler. Some of this may be due to the use of floor registers on the top floor. During the cooling season, air may not be engaging the entire occupied space. Small-diameter systems do a better job of mixing air within rooms and tend to perform better during the "off season" or the cooling season in a heating-dominated climate such as Denver.

None of the townhomes showed significant and repeated temperature drifts or ramps. The builder's standard system tended to cause more abrupt temperature ramps in the conditioned space during on cycles and was picked up as a comfort problem in several instances.

The small-diameter system exhibited shorter median runtimes: 9 min (Home A1) and 10 min (Home A2). Longer runtimes were observed in the builder's standard system: $17 \mathrm{~min}$ (Home B1), 15 min (Home B2), and 28 min (Home B3). The small-diameter systems were sized identically in Home A1 and were 0.5 tons larger in Home A2, compared to the builder's standard matches. The larger system size may have contributed to shorter system cycles. Also, the smalldiameter thermostat may have been more sensitive than that of the standard system and caused the air temperature to reach the top of the dead band more quickly.

In a hot-humid climate, short cycling may result in elevated humidity levels. This was not a concern in the dry Denver climate but should be considered. 
Electric energy consumed during the same period of 9 days was $12.1 \mathrm{kWh} /$ day (Home A1) and $11.4 \mathrm{kWh} /$ day (Home A2) for the small-diameter system and $12.9 \mathrm{kWh} /$ day (Home B1), $10 \mathrm{kWh} /$ day (Home B2), and $11.5 \mathrm{kWh} /$ day (Home B3) for the builder's standard system. The unoccupied unit (Home A3) conditioned with a ductless heat pump system used $15.5 \mathrm{kWh} /$ day. A number of factors may have contributed to the differences in energy consumption, including set point, occupant-related gains, and differences in window treatments.

Ultimately, the data presented in this study represent a very small sample size. A small sample is subject to many uncertainties; however, the small-diameter system proved to show similar, if not better, performance than the traditional system. A study with a much larger sample or a study controlling for many of the real-world uncertainties would provide an absolute comparison of these systems.

What is the measurable air leakage to the party wall between units, to the attic space, or to the garage?

Guarded blower door testing was completed to quantify the air leakage between units. Results from this testing were inconclusive. In one case, the measured leakage area increased when the adjacent unit was depressurized. Attempts to measure the pressure difference across the air barrier between the attic and living space showed no change when adjacent units were depressurized. Because the attics were well vented to the outside, airflow between the attic and outside dominated any airflow that may have occurred through the firewall between attics. Attempts to measure airflow leakage across the garage party-wall assembly also yielded no conclusive results.

The conclusion that can be drawn from this testing is that air leakage between these townhome units through the attached party wall was so minimal that current testing equipment and methods could not detect it. Furthermore, air leakage through the attic party-wall assembly was so low with a well-vented attic that it was negligible.

\section{How does building to DOE Challenge Home standards impact the builder's business?}

The builder's decision to not build the townhome test buildings to Challenge Home standards in this development removed much of the opportunity to evaluate firsthand various business metrics and the impact the shift to Challenge Home would have upon them. However, this builder has a longstanding commitment to building to leading-edge high-performance standards and is building Challenge Home and ZERH single-family homes and townhomes in other developments. A number of business implications are evident, and insights can still be gleaned.

New Town Builders finds that building to a high-performance program such as the DOE Challenge Home program or the DOE ZERH program helps solidify its business model. This builder is somewhat unusual, in that it has committed to providing many of the high-performance features it is already offering. The verification helps the builder tell the story of the benefits that result from the features. Benefits sell better than features sell, according to New Town Builders, because with many buyers, a home purchase is a more emotional decision than a rational one.

The builder is quite confident that its commitments to energy efficiency, environmental friendliness, high performance, and various unique benefits of its home product keep it in 
demand with buyers. This business strategy allows the builder to purchase premium building lots that other builders cannot access. It also opens doors into some Denver metro area developments where some builders cannot sell homes. Developers hear from municipalities that a builder with this business strategy helps the approval process go much more smoothly.

New Town Builders is able to show that it can command a higher profit margin - by about 3\% for the highest-performing home products it offers, such as true net zero packages. There is not necessarily a higher profit margin when building to Challenge Home or ZERH standards. However, doing so is helping this builder maintain its longevity in the market while builders of code and other standard products are being forced out of business because they cannot claim building lots.

Based on this project experience, IBACOS recommends that better insight into the business impacts of building to high-performance programs such as Challenge Home or ZERH could be gleaned by following a builder through the process of evaluating the program and transitioning to becoming a program adopter. Another possibility would be to compare business metrics for a ZERH builder and a non-ZERH builder.

This project is helping the builder find ways to help refine and improve the comfort qualities in its two- and three-story townhomes by reducing stratification. This will help maintain the integrity of the builder's message using the phrase "high performance" for its low-load townhome products.

The builder also has confirmed that although ductless mini-split heat pump systems may offer some advantages, the aesthetics represent a deal-breaker to many buyers. Until the product offerings can evolve to address that issue, these systems do not appear to have a place in this builder's business plans.

\subsection{Additional Lessons Learned}

Several additional lessons learned were captured through the course of this research.

Air handling unit placement, ductwork design, and register location are all critical factors in providing comfort in a home. Current practices for three- or more story homes must recognize the impact that air handling unit location can have on floor-to-floor temperature uniformity. Air handling units should be placed as centrally as possible in the home. Having the air handling unit centrally located provides more opportunity to bring ductwork into conditioned space and increases the inherent balance of the ductwork. Combining long and short duct runs requires more significant work to counter the pressure drop and provide the necessary airflow to each outlet.

In one instance, the small-diameter ductwork had to be rerouted after occupants complained about system noise in a bedroom. This ductwork had bends near the register because of additional framing that had been installed after the duct system was commissioned. Tradespeople need to be properly trained to ensure that the small and flexible ductwork receives priority in placement - a problem that rigid ductwork does not have.

Builders of high-performance homes should consider useful exterior shading and overhangs as more than architectural features; these are functional additions. Good solar orientation and 
design can significantly impact energy consumption. As discussed in preceding sections, the builder installed overhangs and shading devices as architectural features. However, those were installed on the northern façade; as such, they do not reduce solar heat gains. If homebuyers consider these devices attractive, communities have the opportunity to create shading design guidelines that can save energy and provide superior passive comfort.

When installing the small-diameter system, the builder had trouble because no backup heat source was available that could be enabled before the outdoor unit was connected. Builders rely on the furnace to heat homes under construction in the winter season so that drywall can be properly finished and moisture driven from building products. As a temporary solution, the builder used portable propane heaters; however, these created hot spots within the house, and the drywall did not finish well. Furthermore, water as a byproduct of combustion acted as another humidity source within the homes.

To accelerate builder acceptance, new systems need to provide a method of supplying heat as quickly as possible in the construction sequence.

\subsection{Future Work}

Future studies comparing small-diameter space-conditioning systems in multistory buildings should place the central air handling units in similar locations for a more direct comparison of duct performance alone. Furthermore, duct runs should be made as equal as possible to provide consistent outlet temperatures.

Additional work could focus on the variability of installation quality for small-diameter ductwork compared to that of traditionally installed ductwork. This study looked at only six test homes with two HVAC contractors. Performance of either system can be significantly impacted by the quality of ductwork installation. A study comparing the installation quality of a large sample of homes may find one system or the other can be more consistently installed and commissioned. Future air handling equipment designs should focus on being foolproof to install.

Research could investigate the impact of stack effect pressure gradient on return airflow. Return air performance in multistory homes may be limited if the air handling unit is placed on the highest or lowest floor. Small-diameter systems, which operate with a higher plenum static pressure, may be better suited to counter this force. 


\section{References}

ASHRAE. 2013. ANSI/ASHRAE Standard 55-2010, Thermal Environmental Conditions for Human Occupancy. Atlanta, GA: ASHRAE.

Brown, S.A., B.A. Thornton, and S.H. Widder. 2013. Review of Residential Low-Load HVAC Systems (Technical Report). Richland, WA: Pacific Northwest National Laboratory. www.pnnl.gov/main/publications/external/technical reports/PNNL-23017.pdf.

Built Green. 2015. Built Green ${ }^{\circledR}$ Colorado. Built Green, LLC. www.builtgreen.org/.

DOE. 2013. DOE Challenge Home National Program Requirements, Rev. 03. Washington, DC: U.S. Department of

Energy. www.energy.gov/sites/prod/files/2013/11/f5/doe_challenge_home_requirementsv3.pdf.

DOE. 2015. Zero Energy Ready Home Program. Washington, DC: U.S. Department of Energy. http://energy.gov/eere/buildings/zero-energy-ready-home.

EPA. 2015. ENERGY STAR ${ }^{\circledR}$ program. Washington, DC: U.S. Environmental Protection Agency. www.energystar.gov/.

HBA. 2015. Home Builders Association of Metro Denver. Centennial, CO. www.hbadenver.com.

NREL. 2014. BEopt ${ }^{\mathrm{TM}}$ Building Energy Optimization software, Version 2.2.0.1. Golden, CO: National Renewable Energy Laboratory. https://beopt.nrel.gov/.Poerschke, A. 2016. Risk Assessment of Heating, Ventilating, and Air-Conditioning Strategies in Low-Load Homes (Subcontractor Report, NREL/SR-5500-64630). Golden, CO: National Renewable Energy Laboratory. http://www.nrel.gov/docs/fy16osti/64630.pdf.

Poerschke, A., and R. Beach. 2016. Comfort in High-Performance Homes in a Hot and Humid Climate (Subcontractor Report, NREL/SR-64994). Golden, CO: National Renewable Energy Laboratory. http://apps1.eere.energy.gov/buildings/publications/pdfs/building america/highperformance-homes-hot-hum.

Poerschke, A., and D. Stecher. 2014. Simplified Space Conditioning in Low-Load Homes: Results from Pittsburgh, Pennsylvania, New Construction Unoccupied Test House (Subcontractor Report, NREL/SR-5500-62122). Golden, CO: National Renewable Energy Laboratory. www.nrel.gov/docs/fy14osti/62122.pdf.

RESNET. (2015). Home Energy Rating System (HERS $\left.{ }^{\circledR}\right)$. Residential Energy Services Network. www.resnet.us/energy-rating.

Rittelmann, W. 2008. “Thermal Comfort Performance-Field Investigation of a Residential Forced-Air Heating and Cooling System with High Sidewall Supply Air Outlets." Presented at the BEST1 Conference, Minneapolis, MN, June 1-12, 2008. 
Rutkowski, H. 1997. Manual RS-Comfort, Air Quality, and Efficiency by Design. Arlington, VA: Air Conditioning Contractors of America. www.acca.org/technical-manual/manual-rs/.

Rutkowski, H. 2006. Manual J-Residential Load Calculation, 8th edition, Version 2. Arlington, VA: Air Conditioning Contractors of America. www.acca.org/technical-manual/manual-j/.

TopBuild. 2015. Environments For Living ${ }^{\circledR}$ program. Daytona Beach, FL: TopBuild Home Services. $\underline{w w w . e n v i r o n m e n t s f o r l i v i n g . c o m / E F L P u b l i c S i t e / i n d e x . j s p ? a c t i o n=b d ~ p g m ~ d e t a i l s . ~}$ 


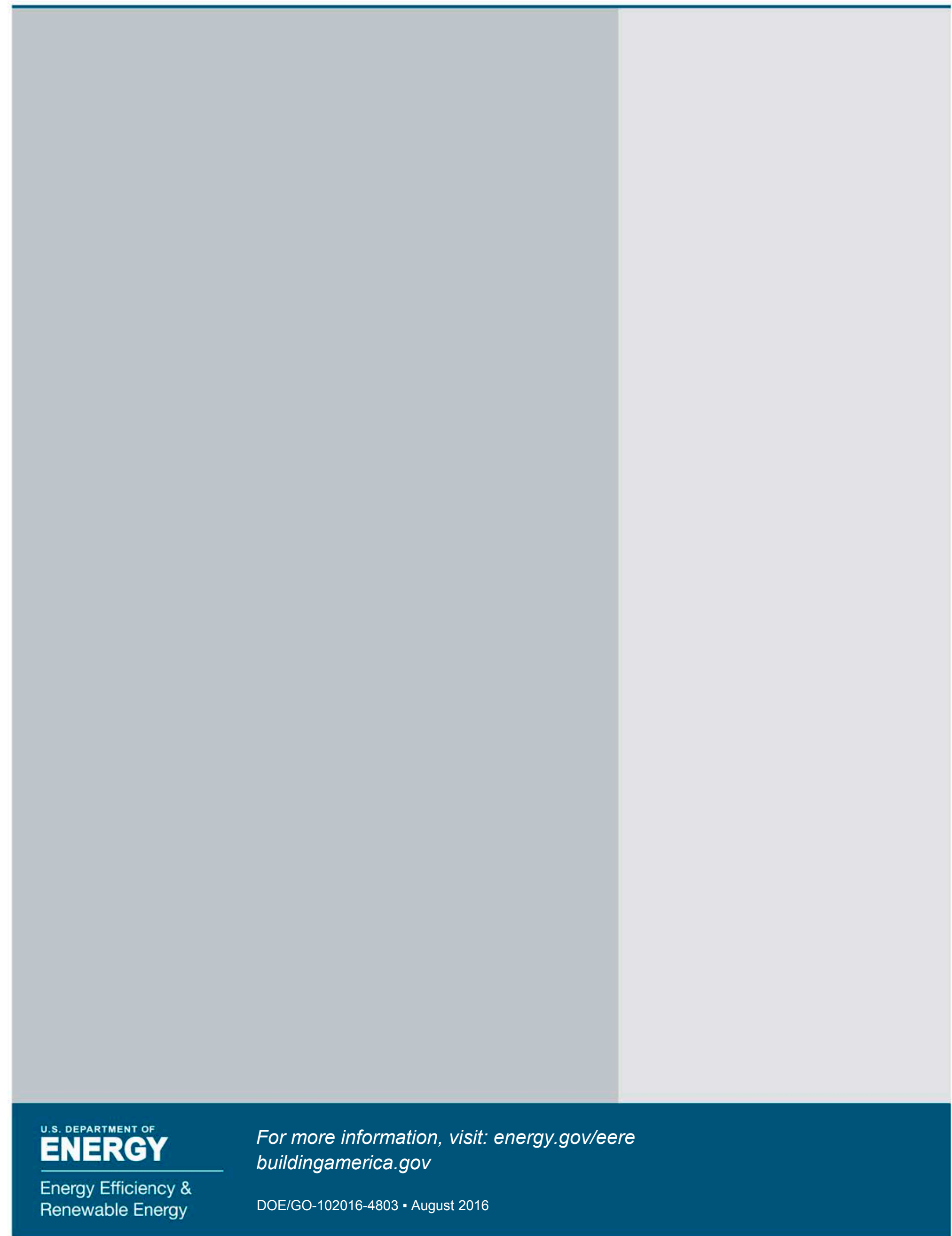

